\title{
A PROTEÇÃO INTEGRAL DOS ÓRFÃOS TERAPÊUTICOS: A VULNERABILIDADE DA SAÚDE DAS CRIANÇAS NO DESENVOLVIMENTO DE NOVOS MEDICAMENTOS
}

THE INTEGRAL PROTECTION OF THERAPEUTIC ORPHANS: THE VULNERABILITY OF CHILDREN'S HEALTH IN THE DEVELOPMENT OF NEW MEDICINES

\author{
Tanise Zago Thomasi ${ }^{1}$ \\ UniCEUB \\ Marcelo Dias Varella ${ }^{2}$ \\ UniCEUB
}

\begin{abstract}
Resumo
Esse artigo analisa o desenvolvimento dos medicamentos pediátricos, estudando, para tanto, o que pode ser considerado desrespeitoso ao direito à saúde infantil, diante da vulnerabilidade das crianças em âmbito internacional e interno. Utilizando um método empírico, o artigo identifica e destaca as práticas farmacêuticas empregadas (conhecidas como "off label" e extrapolação de doses) e sua contrariedade à proteção integral dos seres em desenvolvimento. Os critérios qualitativo e quantitativo utilizados, revelaram omissão informacional aos consumidores de tais fármacos, pois rótulos e bula nacionais, não mencionam a técnica da bioequivalência empregada na sua elaboração. Internamente,
\end{abstract}

${ }^{1}$ Doutoranda em Direito pelo UniCEUB

2 Doutor em Direito pela Universidade de Paris, Panthéon-Sorbonne (2002). Livredocente em Direito Internacional pela Faculdade de Direito da Universidade de São Paulo (2013). Pós-Doutorado em Direito nas Universidades da California, em Berkeley; George Washington; e Georgetown (2011 e 2012). Professor do Programa de Mestrado e Doutorado em Direito do Centro Universitário de Brasília. Foi professor convidado em várias universidades, no Brasil, na França, na Suíça, na Argentina, no México e nos Estados Unidos. Lecionou em diversos cursos para carreiras de Estado, na formação e no curso de altos estudos para diplomatas, para oficiais de chancelaria (MRE), especialistas em políticas públicas e gestão governamental (MP), analistas de comércio exterior (MDIC), advogados públicos (AGU), membros da magistratura e do ministério público, entre outros. Avaliador ad hoc junto a Capes, ao CNPq e a outras agências de fomento internacionais. Bolsista de Produtividade em Pesquisa nível I do CNPq. Autor de livros e artigos científicos no Brasil e no exterior, entre os quais Direito Internacional Público, Saraiva, 6a edição. 


\section{Revista da Faculdade Mineira de Direito $\mid$ V.20 N.40|144}

problematizamos a atuação da Agência Nacional de Vigilância Sanitária, a Anvisa, a partir do recente caso conhecido como "importação da asparaginase chinesa pelo Ministério da Saúde brasileiro". A carência de autonomia da vontade dos menores de idade, impõe redefinições jurídicas quanto à vida, à privacidade, sua discriminação, proibição de tratamentos desumanos e degradantes impactando no seu direito à informação. Contudo, a presente controvérsia envolvendo o tratamento médico infantil, ou seja, a ausência de segurança e eficácia da respectiva droga (asparaginase), não é exclusiva dela. Ao contrário, é característica da grande maioria dos medicamentos pediátricos, desprovidos de comprovação científica adequada, originando a expressão "órfãos terapêuticos". Concluímos, que os protocolos médicos envolvendo menores de idade são negligenciados, não havendo regulamento nacional específico exaustivo sobre o assunto.

Palavras-chave

Medicamento. Crianças. Direito. Informação. Órfão. Terapêutico.

Abstract

This research question the development of pediatric medicines, studying, therefore, what can be considered an offense to the right to children's health, given the vulnerability of children in the international and internal law. The article highlights the pharmaceutical practices known as "off label" and dose extrapolation and their opposition to the integral protection of children. The qualitative and quantitative criteria used revealed informational omission to the consumers of such drugs, since national labels does not mention the bioequivalence technique used in their elaboration. In Brazil, we analyse the National Agency of Sanitary Surveillance Agency, Anvisa, from the recent case known as "import of Chinese asparaginase by the Brazilian Ministry of Health." The lack of autonomy of minors imposes legal redefinitions as to life, privacy, their discrimination, probibition of inbuman and degrading treatment impacting on their right to information. However, the present controversy involving the medical treatment of children, ie the lack of safety and efficacy of the drug (asparaginase), is not a isolated case. On the contrary, it is characteristic of the great majority of pediatric medicines, lacking adequate scientific evidence, giving rise to the expression "therapeutic orphans". We conclude that medical protocols involving minors are neglected, and there is no exhaustive national regulation on the subject.

Keywords

Drugs. Children. Right of information. Therapeutic orphans.

\section{Introdução}

A falta de testes dos medicamentos pediátricos gera um risco para as crianças, ofendendo o direito de acesso à saúde, à informação e à liberdade de escolha ao melhor tratamento. Grande parte dos medicamentos utilizados na pediatria não foi testada em menores de idade, razão pela qual denomina-se esta classe etária como "órfãos terapêuticos 3".

3A expressão aqui empregada é de Shirkey (1968) in SHIRKEY, Harry. Editorial Coment: Therapeutic Orphans. The Journal of Pediatrics, Cincinnati, v. 72, n. 1, p. 


\section{Revista da Faculdade Mineira de Direito $\mid$ v.20 N.40|145}

O foco do trabalho é a discussão acerca das questões jurídicas envolvendo pesquisas circundantes de sujeitos menores de idade, legalmente considerados crianças e, consequentemente, pacientes pediátricos ${ }^{4}$. Nesse sentido, o fato de fisiologicamente o organismo de um paciente infantil ser diferente de um adulto traz o risco de gerar consequências nocivas a curto, meio e longo prazo, pela imprecisão técnica das doses ministradas.

O critério cronológico estabelecido pela Convenção dos Direitos das Crianças foi considerado pelo Comitê dos medicamentos para uso humano (CHMP) determinando que a população pediátrica é composta de neonatos, lactantes e crianças agrupadas, a partir das particularidades de cada faixa etária ${ }^{5}$. A classificação foi considerada devido o rápido crescimento e desenvolvimento infantil impactando a farmacocinética, as respostas farmacodinâmicas das substâncias e reações adversas, baseada na medicina de evidência, diante da escassez de sujeitos de pesquisa menores de idade.

O emprego da técnica da bioequivalência, ou seja, a extrapolação de doses é a solução viável para a carência de testes reais de eficácia e segurança na população pediátrica. $\mathrm{Na}$ prática significa redução de doses dos medicamentos indicados para os doentes adultos no tratamento de moléstias infantis, de acordo com o peso e tamanho corporal do infante, concretizados a partir das características comuns de cada grupo etário, diante das suas particularidades fisiológicas e psicológicas. Outro costume é o uso "off label", ou seja, fármacos são utilizados em crianças, sem nunca

119-120, jan. 1968. Disponível em: <http://www.jpeds.com/article/S0022-

3476(68)80414-7/pdf>. Acesso em: 21 dez. 2016.

4Artigo $1^{\circ}$ da Convenção dos Direitos da Criança. NAÇÕES UNIDAS (ONU).

A/RES/44/25: Convenção sobre os Direitos da Criança. Adotada e aberta para assinatura, ratificação e adesão da Assembleia Geral, em 20 de novembro de 1989, entrada em vigor em 2 de setembro de 1990. Disponível em < http://www.ohchr.org/en/professionalinterest/pages/crc.aspx. Acesso em: 14 jun. 2017. 5 EUROPEAN MEDICINES A GENCY (EMA). Committee for Medicinal Products for Human Use (CHMP). EMEA/CHMP/PEG/194810/2005. Reflection paper: formulations of choice for the paediatric population. London, 28 july 2006. Disponivel em:

$<$ http://www.ema.europa.eu/docs/en_GB/document_library/Scientific_guideline/2009 /09/WC500003782.pdf>. Acesso em: 14 dez. 2016. 


\section{Revista da Faculdade Mineira de Direito | v.20 N.40|146}

ter sido submetidos a estudos clínicos nessa faixa etária, simplesmente, ampliando sua indicação diante da ausência de tratamento específico. Pacientes infantis são compreendidos como "adultos em miniatura", desconsiderando suas singularidades de crescimento, caracterizando, o dilema dos órfãos terapêuticos, ou seja, crianças não possuem terapias médicas adequadas a sua peculiar condição de ser em desenvolvimento.

A razão jurídica para a inexistência de medicamentos próprios às crianças, reside na autonomia da vontade limitada dos menores de idade, ou seja, seus desejos não são considerados. Seus guardiões legais, seja seus pais ou tutores, compete a tarefa de autorizarem sua participação em estudos clínicos, avaliando seus melhores interesses. Porém, no caso específico das terapias medicamentosas infantis (remédios), há um desconhecimento generalizado sobre a escassez de sujeitos de pesquisa a garantir eficácia e segurança comprovadas, além da inexistência de informações adequadas sobre as técnicas utilizadas no desenvolvimento de novos fármacos pediátricos, comprometendo o livre consentimento informado de pacientes e seus guardiões legais, contribuindo para o dilema dos órfãos terapêuticos, dificultando a imposição de limites jurídicos ${ }^{6}$.

Recentemente, a importação pelo Ministério da Saúde brasileiro, da asparaginase chinesa para o tratamento da leucemia infantil, divulgada através dos meios de comunicação nacional, chamou a atenção da população para essa problemática ${ }^{7}$. Em geral, o assunto é desconhecido do grande público e, até, pouco desconsiderada nos meios especializados ${ }^{8}$.

6 RAMET, José. What the paediatricians need the launch of paediatric research in Europe.

European Journal of Pediatrics, Berlin, v. 164, n. 5, p. 263-265, may 2005. Disponível em: <http://dx.doi.org/10.1007/s00431-005-1633-z>. Acesso em: 23 set. 2016.

7 BRASIL. Ministério da Saúde. Secretaria Executiva Subsecretaria de Assuntos Administrativos Coordenação Geral de Material e Patrimônio. Extrato de dispensa de licitação n. ${ }^{\mathbf{0}}$ 62/2017 - UASG 250005. No Processo: 25000049403201653 . Objeto: Aquisição de Asparaginase 10.000UI. Diário Oficial da República Federativa do Brasil. Brasília, 13 de janeiro de 2017, seção 3, p.84. Disponível em < http://pesquisa.in.gov.br/imprensa/jsp/visualiza/index.jsp?jornal=3\&pagina=84\&data= 13/01/2017>. Acesso em 18 jun. 2017.

8 FARMACÊUTICA LEVANTA NOVAS DÚVIDAS SOBRE REMÉDIO PARA CÂNCER INFANTIL .Fantástico. São Paulo. Rede Globo, 2 abr. 2017. PROGRAMA DE TV. Disponível em 


\section{Revista da Faculdade Mineira de Direito $\mid$ V.20 N.40|147}

Contudo, erroneamente, as informações disponibilizadas induzem à compreensão de que apenas esse fármaco não fora devidamente testado, apresentando insegurança no seu uso, sendo que, na prática, grande parte dos produtos pediátricos nunca foi testada em crianças. Cerca de " $80 \%$ dos medicamentos usados em pediatria não são permitidos para crianças e não foram suficientemente testados pela farmacêutica" 9 .

Reconhecemos que muito pouco pode ser concretizado, diante desse impasse ético que impõe uma limitação à indústria farmacêutica. Porém, não compreendemos em que sentido essa omissão informacional, seja através de bulas ou rótulos deve ser mantida, havendo nítida ofensa à legislação consumerista e constituindo prática discriminatória aos direitos infantis ${ }^{10}$.

A gravidade do problema foi acentuada e desvirtuada na imprensa nacional, através do medicamento infantil para leucemia possibilitando a falsa compreensão, de que a Agência Nacional de Vigilância Sanitária, a Anvisa, autorizou a importação de apenas esse fármaco, sem a devida comprovação científica ${ }^{11}$.

O presente artigo apresenta as dificuldades enfrentadas no desenvolvimento de novos medicamentos pediátricos diante da escassez de sujeitos de pesquisa em paradoxo com a proteção integral, instituída na Declaração dos Direitos da Criança. Acentua-se o conflito legal existente entre a autonomia progressiva do menor de idade e o instituto da

<http://g1.globo.com/fantastico/noticia/2017/04/farmaceutica-levanta-novas-duvidassobre-remedio-para-cancer-infantil.html>. Acesso em 15 maio 2017.

9 KRESS, Hartmut. Ética Médica. São Paulo: Loyola, 2008, p. 158.

10 RDC N. ${ }^{\circ} 71$ da ANVISA, apresenta regras para a rotulagem de medicamentos com as informações obrigatórias nas embalagens primárias e secundárias.

11 É o caso do medicamento asparaginase chinesa para o tratamento da leucemia infantil. $\mathrm{Na}$ verdade, a imprensa nacional (Programa Fantástico transmitido pela rede Globo de Televisão) vinculou reportagem afirmando que o respectivo remédio não apresenta segurança e eficácia pediátricas comprovadas, induzindo a população a pensar, ser um caso irresponsável de terapias médicas destinadas ao público infantil. FARMACÊUTICA LEVANTA NOVAS DÚVIDAS SOBRE REMÉDIO PARA CÂNCER INFANTIL. Fantástico. São Paulo. Rede Globo, 2 abr. 2017. PROGRAMA DE TV. Disponível em <http://g1.globo.com/fantastico/noticia/2017/04/farmaceutica-levanta-novas-duvidassobre-remedio-para-cancer-infantil.html>. Acesso em 15 maio 2017. 


\section{Revista da Faculdade Mineira de Direito $\mid$ v.20 N.40|148}

representação jurídica, exercido por seus guardiões (pais ou tutores), em termos da legislação civil nacional e, posteriormente, ao direito da informação e a tomada de decisão esclarecida. Busca-se realçar o dilema dos órfãos terapêuticos apresentando as técnicas utilizadas no desenvolvimento de novos medicamentos pediátricos (extrapolação de doses e "off label"), perpassando pela análise normativa regulatória nesse segmento, demonstrando a negligência nacional quanto à sistematização de publicização dessa realidade. Ademais, pretende-se exemplificar a problemática, com o estudo do conflito da importação da asparaginase chinesa, evidenciando a necessidade de implementação de políticas públicas na rotulagem de medicamentos infantis, aos moldes do que acontece com os remédios genéricos ${ }^{12}$.

\section{Dificuldades nos testes com medicamentos pediátricos}

A medicina de "alta tecnologia" caracterizada pela evolução do conhecimento nessa área proporciona aos sujeitos uma melhor compreensão dos males da vida. Esse avanço encontra-se em uma linha tênue entre os benefícios relativos às condições de vida e os produtos utilizados de forma inadequada para fins obscuros. Neste ínterim, os debates acerca da biotecnologia são cada vez mais pertinentes, principalmente nos estudos sobre o desenvolvimento de medicamentos pediátricos.

Cerca de $27 \%$ da população mundial é composta por crianças, porém, apenas $16,7 \%$ do número total de ensaios registrados são desenvolvidos para esse público-alvo ${ }^{13}$. Mesmo após a tragédia do

12 BRASIL. LEI N ${ }^{\circ}$ 9.787, DE 10 DE FEVEREIRO DE 1999. Altera a Lei no 6.360, de 23 de setembro de 1976, que dispõe sobre a vigilância sanitária, estabelece o medicamento genérico, dispõe sobre a utilização de nomes genéricos em produtos farmacêuticos e dá outras providências. Disponível em

http://www.planalto.gov.br/ccivil 03/leis/L9787.htm. Acesso em 18 jun.2017. 13 JOSEPH DP, CALDWELL PHY, CRAIG JC. Registered paediatric clinical trials: a global context. 2013. Poster presentation International Congress of Pediatrics 2013 (ICP), The 27th Congress of International Pediatric Association 24-29 August 2013 Melbourne, Australia. 


\section{Revista da Faculdade Mineira de Direito | v.20 N.40|149}

envenenamento com dietilenoglicol na década de 1930 nos Estados Unidos e também da catástrofe provocada pela talidomida em $1961{ }^{14}$.

Em 2007, a Organização Mundial de Saúde, através do relatório "Promoting safety of medicines for children" preocupou-se com a monitorização da segurança do uso de medicamentos em crianças, diante dos dados limitados existentes: a detecção, compreensão e prevenção de efeitos adversos ou quaisquer outros problemas relacionados com a medicina, passaram a ser incumbência da farmacovigilância. A partir desse momento, as reações adversas aos medicamentos (ADR) incluindo os erros de medicação, não aderência, sobredosagem, uso fora da etiqueta ("off label"), abuso de efeitos adversos a utilização tradicional ou complementares, passaram timidamente a constituir pauta internacional ${ }^{15}$.

A possibilidade de receber o melhor tratamento em saúde, depende do momento histórico, social, econômico e sanitário em que acontece o encontro entre um indivíduo doente e um médico diante do futuro incerto e da esperança de evitar-se o risco ${ }^{16}$. Todavia, até hoje, os respectivos testes de segurança e eficácia são ínfimos, além de não serem

14 Episódio de 1937, onde a Sulfanilamida (Prontosil), conhecida desde 1932 foi utilizada com sucesso, na forma de pastilhas para o tratamento de infecções por estreptococos. Quando a droga foi lançada na forma de xarope, possuindo como solvente o dietilenoglicol, foi testada sua aparência, gosto e odor, sem nenhuma preocupação com sua segurança, antes do lançamento. O produto provocou a morte de 105 pessoas (34 crianças e 71 adultos). Em 1938 o Congresso Americano aprovou o Food Drug and Cosmetic Act, exigindo dos fabricantes farmacêuticos provas científicas antes da liberação de produtos para sua venda. Naquele tempo milhares de crianças nasceram congenitamente deformadas como resultado da exposição no útero a um medicamento inseguro usado por mulheres grávidas. AGÊNCIA NACIONAL DE VIGILÂNCIA SANITÁRIA (Anvisa) Manual de boas práticas em biodisponibilidade: bioequivalência. Agência Nacional de Vigilância Sanitária. Gerência-Geral de Inspeção e Controle de Medicamentos e Produtos. Brasília: ANVISA, 2002. p.5-6. 15 WORLD HEALTH ORGANIZATION (WHO). Promoting Safety of Medicines for Children. Geneva: World Health Organization, 2007. Disponível em: $<$ http://www.who.int/medicines/publications/essentialmedicines/Promotion_safe_ med_childrens.pdf $>$. Acesso em: 15 dez. 2016.

16 BOBBIO, Marco. O doente imaginado: os riscos de uma medicina sem limites. Tradução Mônica Gonçalvez. 1ª ed. - São Paulo: Bamboo Editorial, 2014, p. 15 e 16. 


\section{Revista da Faculdade Mineira de Direito $\mid$ v.20 N.40|150}

rotulados para crianças, sendo omissos quanto as técnicas empregadas no seu desenvolvimento.

Pacientes pediátricos continuam sendo negligenciados, pois não recebem a mesma qualidade, segurança e eficácia dos medicamentos destinados a população adulta ${ }^{17}$. Há inconsistência com o preconizado pela Organização das Nações Unidas (ONU) e a Convenção do Direitos das Crianças, que visa proteger os seres em desenvolvimento, titulares de todos direitos, mais alguns específicos justificados através do melhor interesse, ou da conhecida proteção integral ${ }^{18}$.

A Declaração Universal dos Direitos Humanos, primeiro documento que reúne normas protetivas a todos os seres humanos, incluiu expressamente o público infantil, os reconhecendo como detentores do "direito à maternidade e a receberem assistência especial, independente de haverem nascido dentro ou fora do matrimônio, gozando de idêntica proteção social"'19.

É dever do Estado garantir acesso aos serviços essenciais de saúde aos menores de idade, incluída atenção anterior e posterior ao parto da mãe, com acesso à informação respeitosa a todos os envolvidos nessa prática. Qualquer desrespeito a essas diretrizes configura discriminação, como consta a "contrario sensu" do mesmo dispositivo. Crianças merecem tratamento igualitário, quanto à alimentação adequada, ao "habitat" seguro e serviços de saúde física e mental ${ }^{20}$.

17 WORLD HEALTH ORGANIZATION (WHO). Promoting Safety of Medicines for Children. Geneva: World Health Organization, 2007. Disponível

em:<http://www.who.int/medicines/publications/essentialmedicines/Promotion_safe_ med_childrens.pdf $>$. Acesso em: 15 dez. 2016.

18 BELOFF, Mary. Derecho, infância y família. Editorial Gedisa. Barcelona, 2000.

p.11

19 Artigo 25 da Declaração Universal dos Direitos Humanos.

20 NAÇÕES UNIDAS (ONU). A/64/272: Derecho de toda personal disfrute del

más alto nível posible de salud física y mental. Observacion General n. ${ }^{\circ} 14$

Proclamada em 11 de agosto de 2000. Disponível em < http://www.acnur.org/t3/fileadmin/Documentos/BDL/2001/1451.pdf >. Acesso em 19 jun. 2017. 


\section{Revista da Faculdade Mineira de Direito | v.20 N.40|151}

Medidas eficazes e apropriadas devem ser adotadas visando pôr fim a práticas tradicionais que as afetem, oportunizando vida satisfatória e decente a capacitá-las a serem membros efetivos da sua comunidade, inclusive tomando posições que prejudiquem sua saúde, adquirindo experiências, a partir do acesso à informação adequada. O exercício desse direito está marcado ainda, pela confidencialidade e a vida privada, garantindo, inclusive, serviços adequados a sua sexualidade e reprodução ${ }^{21}$.

Medidas humanitárias foram as responsáveis pelo atual tratamento compatível e respeitoso a peculiar condição de ser em desenvolvimento, preconizada na Convenção dos Direitos da Criança, que as reconhece como atores de direito internacional, capazes de ostentar certos direitos e liberdades, instituindo a proteção integral ${ }^{22}$.

Considera-se então, criança, todo o indivíduo menor de dezoito anos de idade, a menos que legislação interna específica apresente divergência. E nesse sentido, cada Estado-parte deve proteger cada uma delas, sujeita à sua jurisdição, sem distinção alguma, abrigando-as de discriminação ou castigo por causa da condição, das atividades, das opiniões manifestadas ou das crenças de seus pais, representantes legais ou familiares, priorizando seu direito à vida e sua sobrevivência (artigos $1^{\circ}, 2^{\circ}$, $3^{\circ}$ e $6^{\circ}$ da Convenção).

$\mathrm{Na}$ prática significou a condição de cidadania aos seres em desenvolvimento e a sua respectiva autonomia limitada frente aos guardiões e o Estado, e entre aqueles e estes, a delimitação dessa autoridade.

A ambiguidade do termo "proteção" é a responsável pela existência dos órfãos terapêuticos: crianças são vistas como sujeitos de direitos, com força vinculativa, mas devem ser resguardadas, pelo simples fato de estarem em desenvolvimento mental e social, ou seja, em formação

\footnotetext{
21 NAÇÕES UNIDAS (ONU). A/64/272: Derecho de toda personal disfrute del más alto nível posible de salud física y mental. Observacion General N.. 14 Proclamada em 11 de agosto de 2000. Disponível em < http://www.acnur.org/t3/fileadmin/Documentos/BDL/2001/1451.pdf>. Acesso em 19 jun. 2017.
}

22 BELOFF, Mary. Derecho, infância y família. Editorial Gedisa. Barcelona, 2000. 


\section{Revista da Faculdade Mineira de Direito $\mid$ v.20 N.40|152}

de personalidade e identidade, exigindo respeito e considerações especiais. Problema particular é quanto a criança-família, ou especificamente criança versus representante legal, nas questões sanitárias, ou seja, quando envolve o direito sobre seu próprio corpo.

A “quase" unanimidade da Convenção dos Direitos das Crianças consagrou força jurídica vinculante aos seus preceitos, apesar da forte limitação das obrigações estatais pela oposição de reservas ou declarações, diante da legislação interna ${ }^{23}$.

A modalidade convenção possui "caráter mais amplo, criando normas gerais, ou seja, significa tratado guarda-chuva", exigindo protocolos que criam obrigações concretas para as partes ${ }^{24}$. Sua natureza coercitiva exige a atuação efetiva de cada Estado-parte, que não pode tolerar ofensas aos direitos universalmente aceitos, devendo utilizar mecanismos de controle anteriormente previstos, elevando as políticas públicas e humanitárias para as crianças, garantindo seu bem-estar, diante da vulnerabilidade infantil (artigo 19 da Convenção dos Direitos da Criança).

Obstáculos éticos diante da dificuldade de obter o consentimento informado (da própria criança) comprometem a realização de estudos clínicos apropriados, realizados até então por amostras ínfimas, comparados aos adultos, desafiando por si os princípios estabelecidos na Convenção dos Direitos da Criança ${ }^{25}$. Destacam-se o da não discriminação (artigo $2^{\circ}$ ), o do interesse superior da criança (artigo $3^{\circ}$ ), o do direito à vida

23 Apenas Estados Unidos e Somália não a ratificaram. O artigo 51 afirma ainda, constituir regra consuetudinária de direito internacional, nos termos da qual são inaceitáveis reservas contrárias ao objeto ou finalidade do tratado. NAÇÕES UNIDAS (ONU). A/RES/44/25: Convenção sobre os Direitos da Criança. Adotada e aberta para assinatura, ratificação e adesão da Assembleia Geral, em 20 de novembro de 1989, entrada em vigor em 2 de setembro de 1990. Disponível em < http://www.ohchr.org/en/professionalinterest/pages/crc.aspx. Acesso em: 14 jun. 2017. 24 VARELLA, Marcelo D. Direito Internacional Público. Editora Saraiva. 6. ed. São Paulo, 2016.

25 WORLD HeAlth ORGaniZATION (WHO). Promoting Safety of Medicines for Children. Geneva: World Health Organization, 2007. Disponível em: <http://www.who.int/medicines/publications/essentialmedicines/Promotion_safe_ med_childrens.pdf $>$. Acesso em: 15 dez. 2016. 


\section{Revista da Faculdade Mineira de Direito $\mid$ v.20 N.40|153}

$\left(\operatorname{artigo~} 6^{\circ}\right.$ ) e o da livre expressão (artigo $12^{\circ}$ ), instituindo a relação de "jus cogens" na proteção internacional da infância ${ }^{26}$.

A maturidade, capacidade para formar um juízo próprio, desenvolvimento emocional ou interesse superior da criança é aliado a atuação dos adultos nesse acompanhamento, constituindo a figura dos representantes legais (artigos $5^{\circ}$ e 18$)^{27}$. No âmbito da pesquisa clínica, particularmente o autodeterminismo infantil, necessita ser guiado pelos guardiões, a partir da "percepção do mundo como um lugar onde as pessoas aprendem a fazer valer seus direitos e respeitar os dos demais" 28 . A participação aumenta o poder da criança para garantir seu próprio desenvolvimento e sua própria percepção ${ }^{29}$.

As decisões envolvendo a infância são de grande amplitude, não somente obrigando o legislador, mas também as autoridades, instituições públicas e privadas e seus pais. É uma norma de interpretação, orientação ou diretriz para a formulação de políticas públicas, visando o aperfeiçoamento da vida democrática, devendo "harmonizar a concepção dos direitos humanos como faculdades que permitam oposição aos abusos comuns nessa seara" 30 .

A capacidade progressiva infantil é o pilar jurídico para a redefinição do dilema dos órfãos terapêuticos.

26 MARTINS, Natália Camboa. Sequestro internacional de crianças: análise de posições judiciais sobre as exceções à obrigação de retorno previstas na Convenção de Haia de 1980 sobre os aspectos civis do sequestro internacional de crianças. 2011. 270 p.

Dissertação (Mestrado em Direito) - Programa de Pós Graduação em Direito, Centro Universitário de Brasília, Brasília, 2011.

27 BELOFF, Mary. Protección integral de derechos del niño vs derechos em situacion irregular in Los derechos del niño em el sistema interamericano. Del Puerto, Buenos Aires, 2004. 28 EEKELAR, John. Commentary on "True Wishes" in The Johs Hopkins University Press. PPP/Vol. 2, N. ${ }^{\circ}$ 4/December .1995.

29 UNITED NATIONS CHILDREN'S FUND (UNICEF). Ann Veneman no Prólogo do relatório Situação Mundial da Infância. Edição especial. Novembro de 2009.

Disponível em < https://www.unicef.org/brazil/pt/sowc 20anosCDC.pdf $>$. Acesso em 6 nov. 2016.

30 BRUÑOL, Miguel Cillero. El intersés superior del niño en el marco de la convención internacional sobre los derechos del niño in Infancia, ley y democracia em America Latina. García Méndez y Beloff, Mary (comps.). Ed. Temis/Depalma, Bogotá. 1ª ed. 1998. 


\section{Revista da Faculdade Mineira de Direito | v.20 N.40|154}

Desde o nascimento com vida, o corpo do sujeito passa por uma série de transformações que fisiologicamente os transpõem da condição infantil para a juvenil e, desta feita, considera-se que estes não podem ser resumidos à falsa ideia de estarem na fase do "adulto pequeno", como pretende a indústria farmacêutica ao prescrever para eles, medicamentos voltados para pacientes adultos com doses reduzidas.

No âmbito fisiológico, faz-se necessário compreender que durante os primeiros anos de vida, funções vitais ainda estão em formação o que pode potencializar ou não a toxicidade de determinadas substâncias no organismo.

É público e notório que, se manipulados de forma incorreta, os medicamentos tanto podem curar como causar danos à saúde, o que se denomina como "efeitos colaterais, efeitos secundários e reações adversas" devendo as especificidades do fármaco, estarem claramente postas no produto, ou seja, na conhecida "bula" 31 . Ressalta-se ainda o alto custo de se manter um tratamento médico pediátrico, pois, sem a existência de apresentações indicadas para essa idade, há um grande desperdício da droga, já que no fracionamento ou diluição da substância, grande parte dela é inutilizada.

A indústria farmacêutica enfrenta uma série de dificuldades referentes à aprovação de novos fármacos para uso infanto-juvenil. Em décadas passadas, mais de 50\% dos medicamentos prescritos para crianças nos EUA não eram aprovados ou padronizados para uso pediátrico ${ }^{32}$.

Investigação mundial realizada sobre 11294 receitas para 2947 pacientes pediátricos indicam que quase metade $(49 \%)$ de todas as

31 WORLD HEALTH ORGANIZATION (WHO). Promoting Safety of Medicines for Children. Geneva: World Health Organization, 2007. Disponível em:<http://www.who.int/medicines/publications/essentialmedicines/Promotion_safe_ med_childrens.pdf $>$. Acesso em: 15 dez. 2016.

32 CARVAlHO, Paulo. R. A. CARVALHO, Clarrissa G. ALIEVI, Patrícia T. MARTINBIANCHO, Jaqueline. TROTTA, Eliana A. Identificação de medicamentos "não apropriados para crianças" em prescrições de unidade de tratamento intensivo pediátrico. Jornal de Pediatria. Porto Alegre, v. 79, n. 5, 2003. Disponível em $<$ https://www.inf.pucrs.br/linatural/corporas/pediatria/txt/03-79-05-397port.txt>. Acesso em 16 de set. 2015. 


\section{Revista da Faculdade Mineira de Direito $\mid$ v.20 N.40|155}

prescrições administradas recomendam medicamentos não licenciados, "off label' ou remédios extemporaneamente preparados, para as mais diversas finalidades, sejam elas associadas ao alívio da dor, infecção, prematuridade, nutrição, cirurgia ou anestesia. A droga mais utilizada foi o Paracetamol, carente de informação pediátrica no resumo das características do medicamento (bula). Quanto a neonatos, a taxa correspondente foi de $69 \%{ }^{33}$. Informações prestadas foram inadequadas em $70 \%$ dos $\operatorname{casos}^{34}$.

Assim, para o tratamento das patologias infantis, são utilizadas fórmulas com prescrição diversa do que a bula recomenda, mediante a designação de "off label" ou ainda, a técnica da bioequivalência, que possibilita a extrapolação de doses, a partir de evidências.

A última atitude (a extrapolação), é a responsável, pelo desenvolvimento de medicamentos pediátricos, a similitude do que acontece com os remédios genéricos. Contudo, os consumidores não são devidamente informados desse procedimento, uma vez, que rótulos ou bulas, nada consignam a respeito da ausência de testes reais em crianças, comprometendo a garantia de segurança e eficácia no seu uso, ofendendo o disposto nos incisos II e III do artigo $6^{\circ}$ do Código de Defesa do Consumidor ${ }^{35}$.

Pacientes infantis, na grande maioria das vezes, são "cobaias indiretas", a partir do procedimento de "teste versus erro", uma vez, que estudos clínicos em crianças, são escassos.

33 KIMLAND E., NYDERT P., BÖT'TIGER Y. LINDEMALM S. Paediatric drug use with focus on off-label prescriptions at Swedish hospitals - a Nationwide study. Acta Paediatr (2002) 101 (7):772-8. Disponível em http://onlinelibrary.wiley.com/doi/10.1111/j.1651-2227.2012.02656.x/abstract. Acesso em 3 jan. 2017.

34 ERNEST TB, ELDER DP, MARTINI LG, ROBERTS M, FORD JL. Developing paediatric medicines: identifying the needs and recognizing the challenges. J

Pharm Pharmacol. 2007 Aug;59(8):1043-55. Disponível em < https://www.ncbi.nlm.nih.gov/pubmed/17725846>. Acesso em 13 dez. 2016.

35 BRASIL. LEI N 8.078, DE 11 DE SETEMBRO DE 1990. Dispõe sobre a proteção do consumidor e dá outras providências. Disponível em $<$ http://www.planalto.gov.br/ccivil 03/leis/L8078.htm >. Acesso em 23 jun. 2017. 


\section{Revista da Faculdade Mineira de Direito $\mid$ v.20 N.40|156}

Curiosamente, a prática é desconhecida, inclusive pelos profissionais prescritores, que "parecem ter um mínimo de conhecimento das consequências de suas condutas, com baixo nível de consciência sobre os riscos, efeitos colaterais e resultados de eficácia"36.

Compreendemos a dificuldade em submeter pacientes infantis aos experimentos clínicos capazes de proporcionar segurança e eficácia nos tratamentos curativos, mas não compactuamos com $\mathrm{O}$ desconhecimento generalizado dos procedimentos médicos, eis que os respectivos esclarecimentos são essenciais para uma tomada de decisão, livre por parte do próprio doente ou de seus guardiões legais.

\section{O direito humano à informação diante da decisão livre na} escolha do tratamento médico

O reconhecimento da dignidade humana pressupõe o progresso social e a vida livre a toda pessoa, independente de qualquer distinção. Há responsabilidade da família pela proteção e assistência necessária à criança, que deve crescer em um ambiente de felicidade, amor e compreensão, diante de sua falta de maturidade física e mental. A Convenção dos Direitos da Criança determina expressamente a proteção e cuidados especiais ao ser em desenvolvimento, preconizando sua proteção integral.

É explícita ao afirmar a responsabilidade desempenhada pelos meios de comunicação no acesso a informação que visem promover seu bem-estar social, espiritual e moral, bem como sua saúde física e mental (artigo 17 da Convenção).

Conforme dispõe o artigo 24 desse tratado internacional, as crianças devem gozar do melhor padrão possível de saúde e dos serviços destinados ao tratamento das doenças ao seu restabelecimento. E nesse propósito, os Estados-Partes deverão esforçar-se ao máximo no sentido

36 RAMOS, Karina Alves; JUNGES, Fernanda. O uso off label de medicamentos e a busca por evidências orientadoras de conduta: uma abordagem necessária.

Disponível em < http://www.cpgls.pucgoias.edu.br/7mostra/Artigos/SAUDE\%20E\%20BIOLOGICAS $\angle \mathrm{O} \% 20$ uso $\% 20$ off $\% 20$ label $\% 20 \mathrm{de}^{2} \% 20$ medicamentos $\% 20 \mathrm{e} \% 20 \mathrm{a} \% 20 \mathrm{busca}^{2} \% 20$ por $\% 20 \mathrm{e}$ videncias $\% 20$ orientadoras $\% 20$ de $\% 20$ conduta.pdf $>$. Acesso em 19 jun. 2017. 


\section{Revista da Faculdade Mineira de Direito $\mid$ v.20 N.40|157}

de assegurar serviços sanitários infantis de qualidade, adotando medidas apropriadas na redução da mortalidade infantil, assegurando a prestação de assistência médica e cuidados necessários, além de combater as doenças e desnutrição tendo em vista os perigos e risco da poluição ambiental. Nesse intuito os guardiões legais e as próprias crianças devem conhecer os princípios básicos de saúde e nutrição tendo acesso à educação pertinente com o devido apoio para aplicação dessa sabedoria, de forma preventiva. A cooperação internacional deve ser utilizada progressivamente para a efetivação do direito à saúde infantil, merecendo atenção especial, os países em desenvolvimento.

A própria criança possui direito à manifestação de sua vontade, de acordo com sua compreensão (artigo 12 da Convenção), incluindo a liberdade de procurar, receber e divulgar informações e ideias de todo tipo, independente de sua forma, sendo restrita apenas por determinações legais, em razão da sua liberdade de pensamento, de consciência e de crença (artigo 13 da Convenção). A evolução de sua capacidade, está resguardada, de igual maneira (artigo 14 do mesmo tratado internacional).

A sociedade atual exige pessoas cidadãs e para tanto a informação é a ferramenta que proporcionará esse ajuste, os protegendo e prevenindo de abusos, e melhorando a qualidade de vida dos indivíduos ${ }^{37}$. É ela a responsável pela efetivação de todos os demais direitos, como entendeu a Comissão Interamericana de Direitos no caso Claude Reyes vs. Chile ${ }^{38}$. A partir dele, há avanço considerável quanto ao acesso e transparência de dados públicos, sendo reconhecido como direito humano fundamental, protegido por tratados, obrigando os Estados-Partes a respeitá-lo.

O direito de procurar, receber e difundir informações não deve ser exercido de forma genérica, mas como parte do exercício do "direito à

37 OEA. Inter-American Comissiono n Human Rights. Office of the Special Rapporteur on Freedom of Expression. El derecho de acesso a la informacion em el marco jurídico interamericano. Relatoria especial para la liberdad de expresión. Comisión Interamericana de Derechos Humanos. OEA Ser.L/V/II CIDH/RELE/INF. 2009. 38 CIDH. Comissão Interamericana de Direitos Humanos. Caso Claude Reyes y otros Vs Chile. Sentencia de 19 de septiembre de 2006. Disponível em http:///www.corteidh.or.cr/docs/casos/articulos/seriec 151 esp.pdf. Acesso em 28 out. 2016. 


\section{Revista da Faculdade Mineira de Direito $\mid$ v.20 N.40|158}

liberdade de expressão, tanto na forma de proibição de recebê-la como os outros desejam ou podem estar dispostos a dá-la", como decidido nos casos Gilberg vs Sweden ${ }^{39}$ e Gaskin vs Reino Unido ${ }^{40}$. Dados genéricos são insuficientes, exigindo toda a especificidade requerida, como explicitou o caso Open Door Couseling and Dublin Well Woman vs Irlanda ${ }^{41}$.

Contudo, somente se exerce o que se conhece e, portanto, há muito a ser realizado em termos de informação, quanto aos medicamentos pediátricos, que permanecem omissivos, quanto as técnicas de seu desenvolvimento (emprego da bioequivalência e "off label"), contrariando o princípio da máxima divulgação e, comprometendo, por sua vez, o consentimento livre e esclarecido dos pacientes infantis e seus guardiões legais.

O direito à informação não é absoluto, desde que haja espécie normativa restringindo sua ampla divulgação, de forma justificada, podendo existir dados sigilosos, como o caso da propriedade intelectual. Contudo, a decisão pelo uso de medicamentos deve ser livre e esclarecida, diante dos prós e contras existentes, inclusive, assegurando, o direito de não ser informado, se esse for o desejo do paciente. Está inserida no marco geral da liberdade de expressão, constituindo direito fundamental dos indivíduos ${ }^{42}$.

39 ECRH. Case of Gilberg vs Sweden. Application n. ${ }^{\circ}$ 41723/06. Sentencia de 3 april de 2012 (\$83). Disponível em http://menschenrechte.ac.at/orig/12 2/Gilberg.pdf. Acesso em 28 out. 2016.

40 ECRH. Case of Gaskin vs The United Kingdom. Application n. ${ }^{\circ}$ 10454/83.

Sentencia de 7 july de 1989 (\$53). Disponível em

http://www.juridischeuitspraken.nl/1989070EHRMGaskin.pdf. Acesso em 28 out 2016. 41 ECRH. Case of Open Door and Dublin Well Woman v. Ireland. N. $04 / 1991$ (\$S316/387-388). Council of Europe: European Court of Human Rights, 23 september 1992. Disponível em http://www.refworld.org/docid/3ae6b7020.html. Acesso em 28 out. 2016.

42 CIDH. Comissão interamericana de Direitos Humanos. Acceso a la información en matéria reproductiva desde uma perspectiva de derechos humanos.

OEA/Ser.L/V/II. 22 noviembre 2011. Disponível em https://www.oas.org/es/cidh/mujeres/docs/pdf/ACCESO\%20INFORMACION $\% 20$ MUJERES.pdf. Acesso em 30 out. de 2016. 


\section{Revista da Faculdade Mineira de Direito | v.20 N.40|159}

A informação é elemento essencial aos cuidados de saúde. E no caso dos medicamentos, elas devem estar reunidas nas conhecidas "bulas de remédios", de forma "oportuna, completa, acessível, confiável e informal", sendo disponibilizadas em língua materna e também acessível a pessoas com deficiências, implementadas através das mais variadas formas de comunicação ${ }^{43}$.

A Corte Interamericana de Direitos Humanos e a Corte Europeia de Direitos Humanos são uníssonas em compreendê-la, como violação aos direitos humanos, ainda que a primeira, a classifique como falta de acesso à informação e a segunda, como violação a vida privada. O caso "F.S vs Chile" 44 reconheceu que a falta de compreensão pela vítima, compromete seu livre consentimento informado e no mesmo sentido, o caso "I.V versus Bolivia"45 quando o paciente, não assimilou as demais opções disponíveis ao seu tratamento médico.

A qualidade na prestação é essencial diante da particularidade que o caso exige, considerando ainda o perfil dos envolvidos, sob pena de constituir discriminação, ou seja, distinção, exclusão ou restrição que compromete ou anula o reconhecimento, gozo ou o exercício dos direitos humanos e liberdades fundamentais.

No caso específico dos medicamentos pediátricos, a realidade demonstra que seus consumidores desfrutam de menos serviços de saúde, recebendo menos informações fidedignas pela omissão na divulgação das

43 CIDH. Comissão Interamericana de Direitos. Acceso a la información en matéria reproductiva desde uma perspectiva de derechos humanos. OEA/Ser.L/V/II. 22 noviembre 2011. Disponível em https://www.oas.org/es/cidh/mujeres/docs/pdf/ACCESO\%20INFORMACION\%20 MUJERES.pdf. Acesso em 30 out. de 2016.

44 Mulher de 20 anos foi esterilizada, sem o devido consentimento por não compreender a necessidade do procedimento (era portadora do vírus HIV). CIDH Comissão Interamericana de Direitos Humanos. Caso F.S $\boldsymbol{v}$ Chile. Informe n. ${ }^{\circ}$. 52/14. Peticion 112-09. Disponível em http://www.oas.org/es/cidh/decisiones/2014/CHAD11209ES.pdf. Acesso em 30 out. 2016.

45 CIDH. Comissão Interamericana de Direitos Humanos. Caso I. V vs Bolívia. Informe n. ${ }^{\circ} 40 / 08$. Petition n. ${ }^{\circ} 270-07.3$ de julio de 2008. Disponível em https://www.cidh.oas.org/annualrep/2008sp/Bolivia270-07.sp.htm. Acesso em 30 out. 2016. 


\section{Revista da Faculdade Mineira de Direito $\mid$ v.20 N.40 160}

técnicas empregadas no seu desenvolvimento, em decorrência da escassez de estudos clínicos envolvendo crianças.

Em 1981, a Organização Mundial de Saúde (OMS) em conjunto com o Conselho de Organizações Internacionais de Ciências Médicas (COICM), elaboraram as Diretrizes Internacionais propostas para a pesquisa biomédica com seres humanos, atribuindo responsabilidades ao país sede dos projetos ${ }^{46}$. Preconizou-se então, a criação de um grupo específico para a realização desse estudo, que estivesse em concordância com a diretiva europeia das boas práticas clínicas. Somente em dezembro de 2000, o Conselho Europeu da Saúde solicitou à Comissão providências específicas para remediar a problemática relacionada à indicação inadequada de medicação adulta para os pacientes infanto-juvenis, como informa o documento intitulado "melhores remédios para as crianças" datado de 28 de fevereiro de 2002, no intuito de coibir as práticas "off label' e proporcionar doses medicamentosas infantis adequadas ${ }^{47}$.

No âmbito das pesquisas científicas crianças são seres humanos incapazes, tendo sua autodeterminação restrita aos guardiões (pais ou responsáveis legais), que nem sempre compreendem a verdadeira vontade dos menores, submetendo-os ou não a protocolos médicos sem a devida comprovação, tornando-os "cobaias humanas indiretas", diante da omissão estatal, nessa divulgação.

Estudo de Kress, em cinco unidades médicas com crianças em vários países europeus (Inglaterra, Suécia, Alemanha, Itália, Holanda) apontou que de um universo de 624 crianças com idade de quatro dias a dezesseis anos foram receitados um total de 2.262 remédios, dos quais $46 \%$ haviam sido proibidos ${ }^{48}$. Estudos europeus indicam que "o

46 HOSSNE, W. S. A regulamentação de pesquisas com seres humanos. In Bioética e Saúde Pública. FORTES, P. A. C.; ZOBOLI, E. L. P. (Orgs.). São Paulo: Loyola, 2004. 47COMISSÃO EUROPEIA. Relatório da Comissão ao Parlamento Europeu e ao Conselho. Melhores Medicamentos para Crianças - do Conceito à Realidade. Relatório geral sobre a experiência adquirida com a aplicação do Regulamento (CE) n. ${ }^{\circ}$ 1901/2006 relativo a medicamento para uso pediátrico. Bruxelas, 2013. Disponível em http://ec.europa.eu/health/files/pharmacos/docs/doc2002/feb/cd_pediatrics_en.pdf. Acesso em 22 set. 2015. 48 KRESS, Hartmut. Ética Médica. São Paulo: Edições Loyola, 2008. 


\section{Revista da Faculdade Mineira de Direito $\mid$ V.20 N.40|161}

percentual médio de medicamentos autorizados para crianças entre 19952001 foi de $35 \%$ do total de medicamentos disponíveis comercialmente; sendo que apenas 16 medicamentos foram aprovados para crianças menores de 2 anos de idade (11\%), dez das quais são vacinas49".

Evidente que "quanto mais informada uma pessoa, maior serão suas opções e possibilidades de escolhas" ${ }^{50}$. Porém, nacionalmente, não há indicativos da existência de regulamentação específica quanto aos medicamentos pediátricos.

Para tanto, o desenvolvimento, registro e comercialização de medicamentos pediátricos necessita ser amplamente divulgado, principalmente, para os prescritores, guardiões e pacientes infantis, enquanto elemento da informação, compreensão e voluntariedade.

\section{As práticas cotidianas conhecidas como "off labep" e a extrapolação de doses medicamentosas infantis}

A relutância generalizada em envolver crianças em ensaios clínicos é constante, justamente pelo temor de prejudicá-las, diante da exposição a um tratamento de efeitos incertos ${ }^{51}$. Pesquisa realizada indicou que os genitores compreendem a necessidade da realização de experiências infantis, mostrando vontade em autorizar que seus filhos delas participem, desde que os benefícios sejam claros e evidentes, além de estarem devidamente esclarecidos sobre suas consequências ${ }^{52}$.

49 CECI, A. FELISI M., CATAPANO M., BAIARDI P. CIPOLLINA L., RAVERA S., BAGNULO S. REGGIO S. RONDINI G. Medicines for children licensed by the European Agency for the evaluation of medical products. Eur J Clin Pharmacol, v. 58, p. 495-500, 2002. Disponível em <

https://www.ncbi.nlm.nih.gov/pubmed/12451425>. Acesso em 30 de out. de 2016. 50 GAUDERER, E. C. Os direitos do paciente: um manual de sobrevivência. 6. ed. São Paulo: Record, 1988.

51 CALDWELL, Patrina HY. MURPHY, Sharon B. BUTOW, Phyllis N. CRAIG, Jonathan C. Clinical trials in children. The Lancet: Volume 364, No. 9436, p803-811, 28 August 2004. Disponível em < http://www.thelancet.com/journals/lancet/article/PIIS0140673604169420/abstract $>$. Acesso em 21 dez. de 2016.

52YOUNG, Bridget. SHILLING, Valerie. HICKEY, Helen. SOWDEN, Emma. SMYTH, Rosalind. WILLIAMSON, Paula. What parents think about being approached about 


\section{Revista da Faculdade Mineira de Direito | v.20 N.40|162}

$\mathrm{Na}$ realidade o consentimento informado do guardião é um desafio, quanto a "posição de atuarem como representantes legais, diante da complexidade" científica das experimentações clínicas envolvendo crianças ${ }^{53}$. Estudos demonstraram "aparente discrepância entre a avaliação da adequação das informações transmitidas e a compreensão e memorização dos pais" ${ }^{54}$.

A maioria dos genitores prefere que o médico assuma a responsabilidade nesse processo de decisão ${ }^{55}$. Ainda que, todos eles, "desejem que os medicamentos administrados aos seus filhos apresentem eficácia e segurança, após avaliação apropriada, utilizando estudos baseados em crianças, desde que não seja, no seu filho ${ }^{56}$.

O Código de Nuremberg atentou para o juramento de Hipócrates de não causar o mal aos sujeitos de pesquisa, desde que legalmente sejam

children's trials, how this differs from what practitioners expect, and what this tells us about enhancing recruitment. Trials. 2011; 12(Suppl 1): A116. Published online 2011 Dec 13. doi: 10.1186/1745-6215-12-S1-A116. Disponível em < https://www.ncbi.nlm.nih.gov/pmc/articles/PMC3287689/>. Acesso em 20 de dez. de 2016.

53 CHAPPUY, F. DOZ, S. BLANCHE, GENTET, J-C. TRÉLUYER, J-M. Parental consent in paediatric clinical research. Arch Dis Child. 2006 Feb; 91(2): 112-116. Published online 2005 Oct 24. doi: 10.1136/adc.2005.076141. Disponível em < https://www.ncbi.nlm.nih.gov/pmc/articles/PMC2082705/>. Acesso em 21de dez. de 2016.

54 CHAPPUY, F. DOZ, S. BLANCHE, GENTET, J-C. TRÉLUYER, J-M. Parental consent in paediatric clinical research. Arch Dis Child. 2006 Feb; 91(2): 112-116. Published online 2005 Oct 24. doi: 10.1136/adc.2005.076141. Disponível em < https://www.ncbi.nlm.nih.gov/pmc/articles/PMC2082705/>. Acesso em 21de dez. de 2016.

55 CHAPPUY, F. DOZ, S. BLANCHE, GENTET, J-C. TRÉLUYER, J-M. Parental consent in paediatric clinical research. Arch Dis Child. 2006 Feb; 91(2): 112-116. Published online 2005 Oct 24. doi: 10.1136/adc.2005.076141. Disponível em < https://www.ncbi.nlm.nih.gov/pmc/articles/PMC2082705/>. Acesso em 21de dez. de 2016.

56 SUTCLIFFE, Alastair G. Prescribing medicines for children: Major problems exist, but there are some promising developments. BMJ. 1999 Jul 10; 319(7202): 70-71. Disponível em < https://www.ncbi.nlm.nih.gov/pmc/articles/PMC1116223/>. Acesso em $22 \mathrm{dez}$. de 2016. 


\section{Revista da Faculdade Mineira de Direito $\mid$ v.20 N.40|163}

capazes de dar consentimento livre, ou seja, sem qualquer intervenção de elementos de força, fraude, mentira, coação, astúcia ou forma de restrição posterior ${ }^{57}$. Devem possuir conhecimento suficiente para decidirem, sob dever e responsabilidade do condutor do estudo, não podendo ser realizados de forma casuística ou desnecessariamente. Partem sempre dos resultados já conhecidos e justificados em grau de risco aceitável.

Posteriormente, a Declaração de Helsinki regulamentou princípios científicos visando a revisão ética para pesquisa clínica qualificada, condenando o uso do placebo, quando já existente tratamento eficaz estabelecido. Pretendendo amenizar o sofrimento da humanidade algumas recomendações, como guia na realização de procedimentos biomédicos foram adotados. Especificamente, seu artigo 11 trata da incompetência legal dos menores de idade consentir como sujeitos de estudos clínicos, transferindo a autorização para seu responsável, de acordo com a legislação interna ${ }^{58}$.

É indispensável trazer para o contexto da presente discussão as diretrizes científicas vigentes e seus respectivos mecanismos internacionais de desenvolvimento de medicamentos pediátricos, para posterior discussão jurídica de seus limites.

O licenciamento de medicamentos é responsabilidade do Conselho Internacional de Harmonização ( $\mathrm{ICH}$ ), visando o rigoroso cumprimento de exigências prescritas pretendendo o aperfeiçoamento dos ensaios clínicos, de acordo com as boas práticas farmacêuticas ${ }^{59}$. Essas diretrizes são provenientes do acordo geral entre as agências reguladoras da União Europeia, Japão, Estados Unidos da América, bem como Austrália,

57 Tribunal Internacional de Nuremberg - 1947 - Trials of war criminal before the Nuremberg Military Tribunals. Control Council Law 1949;10(2):181-182. Disponível em https://www.ufrgs.br/bioetica/nuremcod.htm. Acesso em 20 de jun. de 2017.

58 ASSOCIAÇÃO MÉDICA MUNDIAL. Declaração de Helsinki I. Adotada na $18^{a}$ Assembleia Medica Mundial, Helsinki, Finlândia. 1964. Disponível em < https://www.ufrgs.br/bioetica/helsin1.htm>. Acesso em 20 de jun. de 2017 59 WORDL HEALTH ORGANIZATION (WHO). The importance of pharmacovigilance: safety monitoring of medicinal products. Geneva, 2002.

Disponível em http://who.int/iris/bistream/10665/42493/1/a/75646.pdf. Acesso em: 18 de dez. de 2016. 


\section{Revista da Faculdade Mineira de Direito $\mid$ v.20 N.40|164}

Canadá, países nórdicos e a própria Organização Mundial de Saúde (OMS), resguardando a extensão e base de dados de segurança dispostas na ICH E160.

$\mathrm{Na}$ fase de pré-comercialização, os dois atores principais, o fabricante (titular da autorização da introdução no mercado) e as autoridades competentes (agentes reguladores) providenciaram investigações pré-clínicas (toxicidade, mutagenicidade e carcinogenicidade) obrigatórias, apenas. Anterior a essa etapa, acontece um acompanhamento a longo prazo (follow-up) em estudos toxicológicos em animais jovens, buscando o valor preditivo em pediatria, que é incerto, pelas particularidades da criança, ainda que as investigações incluam a farmacodinâmica, a farmacocinética e eficácia ${ }^{61}$.

Se o prognóstico for suficiente, o medicamento está apto à extrapolação de doses, ou a aplicação da técnica de bioequivalência, consistente em apresentações próprias, em quantidade adequada a determinada faixa etária ${ }^{62}$. Seguem, modelo padronizado pela orientação relativa à investigação clínica de medicamentos em crianças (a CPMP $\mathrm{ICH} / 2711 / 99)^{63}$.

60 INTERNATIONAL CONFERENCE ON HARMONISATION OF TECHNICAL REQUIREMENTS FOR REGISTRATION OF PHARMACEUTICALS FOR HUMAN USE (ICH). E1: The extent of population exposure to assess clinical safety for drugs intended for long-term treatment of non-life-threatening conditions. 27 october 1994. Disponível em $<$

http://www.ich.org/fileadmin/Public Web Site/ICH Products/Guidelines/Efficacy/E 1/Step4/E1 Guideline.pdf>. Acesso em: 27 de nov. de 2016.

61 WORld Health ORganization (WHO). Promoting Safety of Medicines

for Children. Geneva: World Health Organization, 2007. Disponível em:<http://www.who.int/medicines/publications/essentialmedicines/Promotion_safe_ med_childrens.pdf $>$. Acesso em: 15 dez. 2016.

62 A Diretiva n. ${ }^{\circ}$ 75/318/CEE, alterada pela Diretiva 1999/82/CE detalha todos esses procedimentos através de seus anexos. Disponível em $<$ http://eur-lex.europa.eu/legalcontent/PT/TXT/PDF/?uri=CELEX:31999L0082\&from=PT>. Acesso em 20 de jun. de 2017

63 EUROPEAN MEDICINES AGENCY (EMEA). ICH Topic $\boldsymbol{E}$ 11: Clinical Investigation of Medicinal Products in the Paediatric Population. Note for Guidance on Clinical products in the paediatric population (CPMP/ICH/2711/99). Disponível em 


\section{Revista da Faculdade Mineira de Direito $\mid$ v.20 N.40|165}

A obtenção de resultados fiáveis a partir da conhecida medicina baseada em evidências, ou seja, aquela que objetiva "separar o trigo dos resultados confiáveis do joio das suposições e, assim, permitir ao médico escolhas racionais e coerentes, reduzir a arbitrariedade, padronizar procedimentos, diagnósticos e tratamentos, dar suporte às decisões de política sanitária" é suficiente para a aprovação e licenciamento do fármaco ${ }^{64}$.

A disponibilidade de medicamentos pediátricos em design infantil (embalagens e formas diversas, como gomas de mascar, comprimidos mastigáveis, pastilhas, entre outros) não imprime total segurança, eis que proveniente da fragmentação de doses adultas, sem definitivamente terem sido "anteriormente" testadas em crianças, diante da técnica da bioequivalência ou extrapolação de doses ${ }^{65}$.

Após a aprovação inicial, os fármacos podem ser estudados em novos regimes de dosagem, novas vias de administração ou indicação para novas populações, podendo ser dispensados novos planos de desenvolvimento ${ }^{66}$.

http://www.ema.europa.eu/docs/en_GB/document_library/Scientific_guideline/2009/ 09/WC500002926.pdf. Acesso em 22 de nov. 2016.

64 BOBBIO, Marco. O doente imaginado: os riscos de uma medicina sem limites. Tradução de Mônica Gonçalves. São Paulo: Bamboo, 2014.

65 INTERNATIONAL CONFERENCE ON HARMONISATION OF TECHNICAL REQUIREMENTS FOR REGISTRATION OF PHARMACEUTICALS FOR HUMAN USE (ICH). M3(R2): Guidance on Nonclinical Safety Studies for the Conduct of Human Clinical Trials and Marketing Authorization for Pharmaceuticals. Geneva, 11 june 2009. Disponível em:

$<$ http://www.ich.org/fileadmin/Public_Web_Site/ICH_Products/Guidelines/Multidisc iplinary/M3_R2/Step4/M3_R2_Guideline.pdf>. Acesso em: 6 dez. 2016.

66 INTERNATIONAL CONFERENCE ON HARMONISATION OF TECHNICAL REQUIREMENTS FOR REGISTRATION OF PHARMACEUTICALS FOR HUMAN USE (ICH). M3(R2): Guidance on Nonclinical Safety Studies for the Conduct of Human Clinical Trials and Marketing Authorization for Pharmaceuticals. Geneva, 11 june 2009. Disponível em:

<http://www.ich.org/fileadmin/Public_Web_Site/ICH_Products/Guidelines/Multidisc iplinary/M3_R2/Step4/M3_R2_Guideline.pdf>. Acesso em: 6 dez. 2016. 


\section{Revista da Faculdade Mineira de Direito | v.20 N.40|166}

Fora dessa situação, está caracterizada a prática do "off label" justamente por não ter sido submetido a comprovação da prova de princípio (indicativo da segurança e eficácia presente no caso da extrapolação de doses). Com certa frequência, pacientes infantis utilizam terapias médicas experimentais (perspectiva do acerto e do erro), sem a devida ciência de seus guardiões, as proclamando a condição de "cobaias indiretas".

As práticas cotidianas acima são o resultado da escassez de ensaios clínicos pediátricos, diante da complexidade do consentimento informado das crianças exercido por seus guardiões legais, como sinônimo da proteção integral.

Os direitos das crianças são interpretados como incapacidade de estabelecerem juízos plenos sobre seus atos e, por conseguinte sua participação por si, ou através de representantes é reduzida ou anulada, em termos jurídicos. A carência de juízo e personalidade é presumida, proporcionando tomadas de decisões que considera o melhor interesse, como secundário, apesar deles impactarem nas suas relações familiares, na sua liberdade, e o desrespeitar na garantia de ser ouvido pessoalmente quanto sua opinião e preferências ${ }^{67}$.

O Conselho Internacional de Harmonização ( $\mathrm{ICH}$ ) permite que medicamentos pediátricos sejam fracionados, dependendo do "conhecimento atual do fármaco e da possibilidade de extrapolação de doses de adultos para crianças em outras faixas etárias", iniciando sempre com as maiores (idade) para finalmente, atender aos bebês ${ }^{68}$.

67 BELLOF, Mary. Modelo de la protección integral de los derechos del niño y de la situação irregular: um modelo para amar y otro para desamar in Justiça y Derechos del niño. Fondo de las Naciones Unidas para la infância. Oficina de Area para Argentina, Chile y Uruguai. Santiago de Chile, novembro de 1999. Disponível em $<$ https:

www.unicef.org/argentina/spanish/ar insumos PEJusticiayderechos1.pdf. $>$. Acesso em 3 mar. 2017.

68 Dados estatísticos de como ocorrem estes estudos, estão disponíveis na ICH Q9.

INTERNATIONAL CONFERENCE ON HARMONISATION OF TECHNICAL REQUIREMENTS FOR REGISTRATION OF PHARMACEUTICALS FOR HUMAN USE (ICH). Q9: Quality Risk Management. 9 November 2005. Disponível em 


\section{Revista da Faculdade Mineira de Direito $\mid$ v.20 N.40|167}

A orientação tenta ajustar as constantes mudanças sociais, econômicas, científicas, tecnológicas entre outras, diante da instabilidade atual e, neste contexto, a ciência do direito não vem apresentando velocidade de evolução, ou seja, vivencia-se uma marca de transformações cujos impactos não se pode mensurar se ocorrem para melhor ou pior, simplesmente, as direções de sentido alteram-se sem uma lógica ${ }^{69}$.

A própria relação médica original nada mais é do que um contrato fiduciário, apesar de caracterizado pela pessoalidade, exigindo que o terapeuta seja um depositário da confiança, baseado principalmente na lealdade daquele para com seu cliente visando ao máximo de bem-estar. Conjuntamente aparece a necessidade de confiar-se fielmente naquilo que é informado, fazendo com que todos se comprometam com o conforto das pessoas, principalmente as vulneráveis, afiançando uma relação de convicção e certeza, que tornará mais estreitos os laços entre o paciente e o profissional da saúde.

No âmbito da ética, ressalta-se a possível ocorrência da "falsidade benevolente", ou seja, questiona se é moralmente justificável não revelar a verdade clínica no intuito de proteger o doente, já que esta atitude não garante antecipar as consequências que a informação ou a falta dela causará na realidade.

Certo é, que, a medicalização na vida é necessária e indispensável nos dias de hoje, seja pela intervenção técnica no organismo, a imperiosidade do reestabelecimento das condições básicas de sobrevivência e o sistema industrial que movimenta, a partir da biotecnologia. Por vezes, retira do indivíduo todo o poder de decisão, justamente para controlar politicamente o sistema. A medicina passa a ser uma "oficina de reparos e manutenção destinada a conservar em funcionamento o homem usado como produto não humano" 70 .

https://www.ich.org/fileadmin/Public Web Site/ICH Products/Guidelines/Quality/ Q9/Step4/Q9 Guideline.pdf.Acesso em 6 dez. 2016.

69 VARELLA, Marcelo D. Internacionalização do Direito: direito internacional, globalização e complexidade/ - Brasília: UniCEUB, 2013.

70 ILLICH. Ivan. A expropriação da saúde. Nemesis da Medicina. Tradução de José Kosinski de Calvancanti. $3^{a}$ ed. Editora Nova Fronteira, 1975. 


\section{Revista da Faculdade Mineira de Direito $\mid$ v.20 N.40|168}

Contudo, além das diretrizes de harmonização, nada há quanto ao desenvolvimento de medicamentos pediátricos constituindo vazio ou lacuna legal, compatível, com novéis regulamentações, sobre o tema.

O artigo 37 da Convenção dos Direitos da Criança reafirma responsabilidade estatal no tratamento sanitário dispensando aos seres em desenvolvimento, quando são cerceados em suas liberdades de forma arbitrária. Ademais, sua proteção integral e simultânea de desenvolvimento exige qualidade de vida adequada, de acordo com o artigo 27.1, do mesmo tratado internacional.

O paciente infantil é sujeito de direitos e, portanto, livre para suas escolhas individuais, de acordo com sua maturidade, não devendo ser submetido a tratamentos médicos experimentais, sem sua ciência própria, ou de seus guardiões, em casos de incapacidades específicas.

Percebe-se a necessidade de regulamentação nacional para licenciamento de medicamentos pediátricos enquanto uma alternativa viável capaz de garantir ações regulatórias que sejam mais eficazes e seguras, pois a atual dinâmica tornou-se uma barreira no respeito aos direitos das crianças, tornando-os mais vulneráveis aos procedimentos terapêuticos, enfatizando que nem mesmo o direito à informação é considerado no consumo de remédios infantis.

$O$ ponto de equilíbrio ainda deve ser encontrado, para que seja assegurada a autonomia do indivíduo aliada às próprias políticas públicas que garantem o acesso às condições da vida saudável e, em casos de patologias, acesso aos meios terapêuticos e profiláticos existentes. Tal conflito se acentua quando esses procedimentos ainda não são considerados confiáveis, em decorrência da falta de estudos e também da capacidade de escolha do menor de idade, que passa a ser desconsiderado para a legislação, pois só adquirirá capacidade ao completar dezoito anos, nos termos do artigo $3^{\circ}$ do atual Código Civil ${ }^{71}$.

A literatura aponta não haver significativa mobilização brasileira para a temática da autodeterminação do menor em termos sanitários, não

71 BRASIL. LEI No 10.406, DE 10 DE JANEIRO DE 2002. Institui o Código Civil.

Disponível em < http://www.planalto.gov.br/ccivil 03/leis/2002/L10406.htm >.

Acesso em 20 jun. 2017. 


\section{Revista da Faculdade Mineira de Direito $\mid$ v.20 N.40|169}

havendo nenhuma legislação a respeito, com exceção para o tímido artigo 74 do Código de Ética Médica, que garante o sigilo da informação, até mesmo quando os interessados são os representantes legais, respaldando a privacidade infantil, como espécie de direito humano.

Exceto essa disposição, os pacientes infantis são negligenciados, pois o "maior insulto à santidade da vida é a indiferença ou a preguiça diante de sua complexidade" 72 . O caso da importação da aspartaginase chinesa é o exemplo mais recente da problemática, instigando a população nacional a sensibilizar-se sobre os órfãos terapêuticos, ainda inédita, para a grande maioria da população.

\section{$4 \mathrm{O}$ atual cenário dos medicamentos pediátricos}

Há várias iniciativas para a regulação dos medicamentos para crianças, como a Rede Europeia de Investigação Pediátrica estabelecida na Agência Europeia de Avaliação de Medicamentos (EMA) ${ }^{73}$. Contudo, dados dos relatórios prévios sinalizam que não houve avanço significativo dos estudos clínicos envolvendo crianças, porém, ressaltam que no final de 2011 já tinham sido aprovadas 72 novas indicações pediátricas para medicamentos, incluindo 30 indicações decorrentes dessas obrigações. Em 2012 algumas alterações legislativas visando impor sanções financeiras em caso de descumprimento foram adotadas.

Nos Estados Unidos, a lei dos medicamentos órfãos, de 1983, conhecida como "Orphan Drug Act", demonstra a preocupação com o problema. O documento "melhores medicamentos para crianças (Best Pharmaceutical for Children Act - BPCA)", informa que existem regras específicas para incentivar a realização de ensaios clínicos com estes

72 DWORKIN, Ronald. Domínio da vida: aborto, eutanásia e liberdades individuais. São Paulo: Martins Fontes, 2003, p.343.

$73 \mathrm{O}$ uso dos medicamentos pediátricos, na União Europeia, foram publicados em dezembro de 2010 (art. 42 ) e serviram de base ao inventário das necessidades terapêuticas $\left(\operatorname{art} .43^{\circ}\right.$ ). Disponíveis a consulta pública, desde março de 2011, no site «clinicaltrialregister.eu». 


\section{Revista da Faculdade Mineira de Direito $\mid$ v.20 N.40|170}

pacientes $^{74}$. São conhecidas como "regra pediátrica" e "exclusividade pediátrica", aprovadas em 1997 e 1998, respectivamente75. Quanto à primeira, exige que haja um número considerável de pacientes pediátricos para justificar o benefício em relação aos tratamentos existentes. Já a segunda, fornece um incentivo de seis meses adicionais de exclusividade ou proteção de patente sobre a porção ativa, para as empresas que realizam esses estudos dentro dos indicadores de saúde pública, independente dos resultados obtidos. No entanto, a "exclusividade pediátrica" exige a elaboração de orientações assim como a "lista pediátrica", contendo as informações específicas, tais como, sua apresentação e posologia ${ }^{76}$. Posteriormente, a ideia de lista foi abandonada. A regra pediátrica (Pediatric Rule, ou ainda o Best Pharmacenticals Act), promulgada em janeiro de 2002, renovou a exclusividade pediátrica (Pediatric Exclusivity Provision), no sentido de responder aos pedidos escritos e resultantes das novas informações infantis dos rótulos, de forma a tornar acessível à indicação da posologia para crianças ${ }^{77}$.

Ademais, em determinados casos pode exigir o desenvolvimento de uma fórmula exclusivamente pediátrica, normalmente, em solução para

74 COMISSÃO EUROPEIA. Relatório da Comissão ao Parlamento Europeu e ao Conselho. Melhores Medicamentos para Crianças - do Conceito à Realidade. Relatório geral sobre a experiência adquirida com a aplicação do Regulamento (CE) n. ${ }^{o}$ 1901/2006 relativo a medicamento para uso pediátrico. Bruxelas, 2013. Disponível em http://ec.europa.eu/health/files/pharmacos/docs/doc2002/feb/cd_pediatrics_en.pdf. Acesso em 22 de set. 2015.

75 WORLD HeAlth ORGANIZATION (WHO). Promoting Safety of Medicines for Children. Geneva: World Health Organization, 2007. Disponível em: <http://www.who.int/medicines/publications/essentialmedicines/Promotion_safe_ med_childrens.pdf $>$. Acesso em: 15 dez. 2016.

76ROBERTS, Rosemary. RODRIGUEZ, William. MURPHY, Dianne. CRESCENZI, Terri. Pediatric drug labeling: improving the safety and eficacy of pediatric therapies. Journal of the American Medical Association, v. 290, p. 905-911, 2003. Disponível em <http://jamanetwork.com/journals/jama/fullarticle/197130>. Acesso em 3 jan. 2017. 77 ROBERTS, Rosemary. RODRIGUEZ, William. MURPHY, Dianne. CRESCENZI, Terri. Pediatric drug labeling: improving the safety and eficacy of pediatric therapies.

Journal of the American Medical Association, v. 290, p. 905-911, 2003. Disponível em < http://jamanetwork.com/journals/jama/fullarticle/197130>. Acesso em 3 jan. 2017. 


\section{Revista da Faculdade Mineira de Direito $\mid$ V.20 N.40|171}

facilitar a ingestão por esse público alvo. Após três anos de aplicação, a cláusula de "exclusividade" foi revisada pelo Congresso dos Estados Unidos $^{78}$.

A União Europeia também disciplinou a matéria (Regulamento n. ${ }^{\circ}$ 1902/2006) visando ampliar a segurança dos medicamentos para crianças, aumentando a investigação, desenvolvimento e autorização com base na experiência médica, sem submeter à população pediátrica a ensaios clínicos desnecessários, através de diretrizes próprias, orientando o formato e o conteúdo dessas práticas ${ }^{79}$.

Apesar da ocorrência de ações pontuais e pouco recorrentes acerca desta problemática relacionada ao tratamento infanto-juvenil e as indústrias farmacêuticas, existem outros países demonstrando preocupação quanto aos direitos dos pacientes pediátricos, consubstanciados através de determinações governamentais que criaram diferentes e variados incentivos financeiros em todo o mundo.

$\mathrm{O}$ acesso aos medicamentos pediátricos deve ser aprimorado de acordo com o desenvolvimento social, tecnológico e científico ${ }^{80}$. Necessitam serem disponíveis, acessíveis e de boa qualidade, a partir de informação confiável aos pacientes e profissionais da saúde, a fim de que as decisões sejam bem fundamentadas, as utilizando de forma segura ${ }^{81}$. A

78ROBERTS, Rosemary. RODRIGUEZ, William. MURPHY, Dianne. CRESCENZI, Terri. Pediatric drug labeling: improving the safety and eficacy of pediatric therapies.

Journal of the American Medical Association, v. 290, p. 905-911, 2003. Disponível em < http://jamanetwork.com/journals/jama/fullarticle/197130>. Acesso em 3 jan. 2017.

79 WORLD HEALTH ORGANIZATION (WHO). Promoting Safety of Medicines for Children. Geneva: World Health Organization, 2007. Disponível em: $<$ http://www.who.int/medicines/publications/essentialmedicines/Promotion_safe_ med_childrens.pdf $>$. Acesso em: 15 dez. 2016 80 CARVALHO, Patrícia Luciane de. Patentes Farmacêuticas e acesso a medicamentos. São Paulo: Atlas, 2007.

81 HUNT, Paul; KHOSLA, Rajat. Acesso a medicamentos como um direito humano. Sur - Revista Internacional de Direitos Humanos, São Paulo, v. 5, n. 8, p. 100-121 jun. 2008. Disponível em: < http://www.scielo.br/pdf/sur/v5n8/v5n8a06.pdf> Acesso em: 15 fev. 2017. 


\section{Revista da Faculdade Mineira de Direito | v.20 N.40|172}

inércia passa a ser inadmissível. Dados globais e regionais infantis são escassos.

A Organização Mundial de Saúde estabeleceu a política da lista de medicamentos essenciais, consistente em uma relação estabelecida a partir de 1975, considerando a "seleção e obtenção, a um custo razoável, da qualidade de fármacos correspondentes às necessidades sanitárias" 82. Porém, a primeira lista pediátrica foi inaugurada em maio de 2007. Admite flexibilizações e adaptações em situações diversas, justamente por basearse em evidências, decorrente da "falta de medicamentos adequados para crianças no mundo" 83 .

Os Estados-Partes devem disponibilizar medicamentos essenciais que "figuram en las Listas Modelos de Medicamentos Essenciales de la Organización Mundial e la Salud, incluídas las listas de medicamentos para niños (en formulas pediátricas, cuando es posible) resultem disponibles, acessibles y asequibles" 84 . A particularidade existente no desenvolvimento de medicamentos pediátricos é considerada, quando atenta para a inexistência de fórmulas específicas para essa faixa etária, inclusive quanto aos remédios essenciais.

82 WORLD HEALTH ORGANIZATION (WHO). The use of essential drugs: Ninth report of the WHO Expert Committee (including the revised Model List of Essential Drugs). Geneva: World Health Organization, 2000. (WHO technical report series, 895).

Disponível em:

<http://apps.who.int/iris/bitstream/10665/42373/1/WHO_TRS_895.pdf>. Acesso em: 9 dez. 2016.

83 COELHO, Helena Lutéscia 1., REY, Luís Carlos, MEDEIROS, Marina S.G. de, BARBOSA, Ronaldo A., FONSECA e Said G. da Cruz e COSTA, Patrícia Q. A critical comparison between the Wordl Health Organization list of essential medicines for children and the Brazilian listo f essential medicine (RENAME) in J Pediatr (Rio J), 2013; 89(2): 171-178. Disponível em $<$ http:apps.who.int/medicinedocs/documents/s22184pt/s22184pt.pdf $>$. Acesso em $27 / 1 / 2017$.

84 NACIONES UNIDAS (ONU). Comité de los Derechos del Niño. CRC/C/GC/15: Observación general No 15 (2013) sobre el derecho del niño al disfrute del más alto nivel posible de salud (artículo 24). Ginebra, 17 abr. 2013. Disponível em: $<$ http://www.codajic.org/sites/www.codajic.org/files/Convenci $\%$ C3 $\%$ B3n $\% 20$ sobre $\%$ $20 \mathrm{los} \% 20 \mathrm{Derechos} \% 20 \mathrm{del} \% 20 \mathrm{NI} \% \mathrm{C} 3 \%$ B1o\%20.GC_.15_sp_0.pdf>. Acesso em: 13 nov. 2016 


\section{Revista da Faculdade Mineira de Direito $\mid$ v.20 N.40|173}

Hoje, está em vigência a $6^{\circ}$ Lista de Medicamentos Essenciais para Crianças (LMEc) considerando as práticas cotidianas quanto ao desenvolvimento de fórmulas específicas, baseada em evidências, ou seja, representada pelas necessidades básicas mínimas para um sistema básico de saúde 85 .

O direito internacional necessita agir em favor dos órfãos terapêuticos, através do suporte técnico interdisciplinar, propondo normas jurídicas compatíveis com o princípio da não discriminação em suas terapias médicas mundiais.

\section{A regulação nacional dos medicamentos pediátricos}

Internamente, a primeira preocupação brasileira em pesquisa sanitária ocorreu com a necessidade de comprovação de segurança e eficácia de medicamentos através da Lei n. ${ }^{\circ}$ 6360/76 conhecida por exigir a análise a partir de comprovação científica, visando cuidar da saúde da população.

O Conselho Nacional de Saúde, através da Resolução n. ${ }^{\circ}$ 01/88 disciplinou que a indústria farmacêutica deve "mesclar a ética das pesquisas com questões e aspectos da biossegurança e de vigilância sanitária"86. Pesquisa clínica envolvendo seres humanos foi então conceituada, através da Resolução n. ${ }^{\circ}$ 196/96 como multidisciplinar, cuja aceitação não esteja consagrada na literatura científica, sejam elas farmacológicas, clínicas ou cirúrgicas e de finalidade preventiva, diagnóstica ou terapêutica. Ressalta-se que enquanto complementaridade determina ainda a proteção da imagem e a não-estigmatização, assegurando a confidencialidade e a privacidade, além da garantia do retorno dos benefícios obtidos através das pesquisas para as pessoas e as comunidades.

85 WORLD HEALTH ORGANIZATION (WHO). 6th List. Model List of Essential Medicines for Children. 6th List. March 2017. Disponível em http:/ /www.who.int/medicines/publications/essentialmedicines/6th_EMLc2017.pdf?ua =1. Acesso em 20 jun. 2017.

86 HOSSNE, W. S. A regulamentação de pesquisas com seres humanos. In Bioética e Saúde Pública. FORTES, P. A. C.; ZOBOLI, E. L. P. (Orgs.). São Paulo: Loyola, 2004. 


\section{Revista da Faculdade Mineira de Direito | v.20 N.40|174}

A Anvisa não diferencia sua atuação enquanto público-alvo, sendo omissa quanto ao tratamento dispensado aos pacientes infantis e consequentemente, ao desenvolvimento deles. $\quad \mathrm{O}$ Brasil atento ao cumprimento das regulações internacionais de ações seguras no desenvolvimento de novos fármacos, redefiniu sua política através da RDC n. 9 de 20 de fevereiro de 2015, visando sua desburocratização e agilidade em conformidade com o disposto na ICH E6(R1). A partir de maio de 2016, as avaliações dos respectivos planos de desenvolvimento dos ensaios clínicos realizados nacionalmente, nada de específico consta, mantendo a omissão característica do assunto.

Aliás, a análise é realizada de acordo com a classe do produto, independente do público-alvo ${ }^{87}$. A RDC n. ${ }^{\circ}$ 9/2015 permite através de Comunicado Especial a importação ou exportação de ensaios clínicos, indicando quais produtos estão autorizados a serem utilizados, diante da RDC n. ${ }^{\circ}$ 60/2014, que exige na proposta de plano de desenvolvimento o modelo da bula e layout da embalagem, bem como as demais características, se o produto for proveniente de importação ${ }^{88}$.

Os requisitos de registro de acordo com a finalidade do medicamento estão dispostos no capítulo III dessa resolução, admitindo plano de minimização de risco (responsável pelo não cumprimento de todas as fases de pesquisa) e em análise de medicamento comercializado em outros países (artigo 24).

Essa minimização de risco, que abrevia as etapas de desenvolvimento de fármacos, é responsável pelos medicamentos pediátricos, não sendo analisadas características etárias, e sim, a correspondente classe de produtos. As doses extrapoladas são o resultado do pós-registro de nova forma farmacêutica, nova concentração, nova via de administração e nova indicação terapêutica, admitindo, a biodisponibilidade relativa quando o medicamento proposto estiver dentro da faixa etária adequada ${ }^{89}$.

87 Entre sintéticos, biológicos, fitoterápicos, radiofármacos, além dos específicos. 88 Agência Nacional de Vigilância Sanitária (Anvisa). Manual para notificação de eventos adversos e monitoramento de segurança em ensaios clínicos. Brasília. Anvisa. 2016. 89 Vide artigos 30 a 37 da RDC n. ${ }^{\circ}$ 60/2014 da ANVISA. 


\section{Revista da Faculdade Mineira de Direito $\mid$ v.20 N.40|175}

Medicamentos pediátricos nacionais são autorizados a partir da biodisponibilidade, ou seja, mesma técnica utilizada no desenvolvimento dos remédios genéricos, permitida nacionalmente com a promulgação da Lei n. ${ }^{\circ}$ 9.787/99. Assim, são liberados para consumo a partir da comparação: "equivalência na mesma forma farmacêutica e quantidade do princípio ativo, que ao serem administrados nas mesmas condições experimentais, não apresentam diferenças estatisticamente significativas" 90 .

O estudo tradicional da bioequivalência exige a participação de 24 a 36 voluntários, sendo que na falta de dados relativos ao coeficiente de variação, é recomendado a realização de um estudo piloto para constatálos, em média com 12 pessoas, diante das possíveis intercorrências provenientes de desistências e eventos adversos associados à medicação ${ }^{91}$.

A segurança dos medicamentos pediátricos é ínfima diante das razões mercadológicas relacionadas às políticas de investimentos e, talvez, por falta de fundamentação legal ou estímulo pelos órgãos oficiais de controle, a indústria farmacêutica não tem demostrado e agido com o devido comprometimento nesse segmento. Aliás, demonstram que medicamentos comumente utilizados em prescrições pediátricas são classificados como não padronizados, a exemplo do Paracetamol ou ainda como não aprovados, a citar a Dipirona, entre os mais utilizados como o aerossol de Sabultamol, Metoclopramida, Fenitoína e Ondansetron, sem doses infantis estabelecidas ${ }^{92}$.

90 Agência Nacional de Vigilância Sanitária (Anvisa). Manual das boas práticas em biodisponibilidade: bioequivalência/Agência Nacional de Vigilância Sanitária. Gerência Geral de Inspeção e Controle de Medicamentos e Produtos. Brasília. ANVISA, 2002. 91 REDIGUIERI, Camila Fracalossi; SOUZA, Varley Dias. Estudos de Bioequivalênca. In: VIEIRA, Fernanda Pires; REDIGUIERI, Camila Fracalossi; REDIGUIERI, Carolina Fracalossi. (Orgs.). A regulação de medicamentos no Brasil. Porto Alegre: Artmed, 2013. p. 237-290.

92 CARVALHO, Paulo. R. A. CARVALHO, Clarrissa G. ALIEVI, Patrícia T.

MARTINBIANCHO, Jaqueline. TROTTA, Eliana. Identificação de medicamentos "não apropriados para crianças" em prescrições de unidade de tratamento intensivo pediátrico.

Jornal de Pediatria. Porto Alegre, v. 79, n. 5, 2003. Disponível em

<https://www.inf.pucrs.br/linatural/corporas/pediatria/txt/03-79-05-397port.txt>.

Acesso em 16 de set. 2015 


\section{Revista da Faculdade Mineira de Direito | v.20 N.40|176}

A eficácia e segurança ocorrem a partir da técnica conhecida como bioisenção, ou seja, a partir de estudos "in vitro como prova da equivalência terapêutica, substituindo os estudos in vivo para alguns produtos"93. A extrapolação de doses é permitida, ainda que não divulgada ${ }^{94}$.

A partir deste viés de entendimento, pode-se inferir que não há diagnósticos precisos, e assim a problemática dos órfãos terapêuticos está reconstruindo seu próprio sentido através da sua cláusula de abertura, assim como das comunicações existentes, tendo em vista o fato de que todos têm direito à saúde, apesar de poucos desfrutarem dela em conformidade com os termos do conceito preconizado pela Organização Mundial de Saúde.

A Constituição Federal de 1988 classifica a saúde como um dos direitos sociais, previstos no seu artigo $6^{\circ}$, cuja efetivação é atribuição delegada ao Estado, de acordo com o artigo 196 do mesmo dispositivo legal. Assim, sua promoção e desenvolvimento é uma tarefa governamental a ser compartilhada entre toda a sociedade, considerando o mais alto nível que puder ser alcançado como direito fundamental de cada ser humano. Os progressos da ciência e da tecnologia devem fomentar o acesso a uma atenção médica de qualidade e aos medicamentos essenciais, especialmente para a saúde das crianças.

Atendendo a essa vertente, o Brasil adotou na referida Constituição, os elementos necessários para a criação do Sistema Único de Saúde (SUS), contemplando os cuidados e a atenção com a saúde como um direito social e dever do Estado, ampliando a visão integral do homem ao adicionar a este o direito ao meio ambiente equilibrado - artigo 225 do mesmo dispositivo legal - como essencial para a qualidade de vida.

O Sistema Único de Saúde (SUS) foi implantado com a Constituição Federal de 1988, assemelhando-se em alguns aspectos ao

93 REDIGUIERI, Camila Fracalossi; SOARES, Kelen; CARRIJO, Kalinka de Melo.

Bioisenção. In: VIEIRA, Fernanda Pires; REDIGUIERI, Camila Fracalossi;

REDIGUIERI, Carolina Fracalossi. (Orgs.). A regulação de medicamentos no Brasil. Porto Alegre: Artmed, 2013. p. 320-336.

94 Artigo $5^{\circ}$ da RDC n. $37 / 2011$ da Anvisa. 


\section{Revista da Faculdade Mineira de Direito $\mid$ v.20 N.40|177}

sistema francês de saúde, possuindo também em sua elaboração inicial particularidades relacionadas ao modelo americano, como por exemplo, a exigência da implementação de políticas públicas visando uma atuação positiva do Estado-nação. Mediante tal formulação, objetivou como prioridade que a redução do risco de doenças e outros agravos deveriam ocorrer de forma igualitária a todos os residentes em território nacional, sendo capaz de promover a proteção e recuperação dos indivíduos, através de convênio, com a iniciativa privada, em concordância com os termos do artigo 128 da CF.

Neste ínterim, ressalta-se a tríade da integralidade, igualdade e participação da comunidade, regulamentada pela Lei n. ${ }^{\circ}$ 8080/90. Estabelecida nas três esferas do poder, que dizem respeito à aplicação das ações e serviços da saúde, respeitando o artigo 25 da Declaração Universal dos Direitos do Homem e efetivando a obrigação estatal de garanti-la enquanto direito fundamental que corrobora para a efetivação dos preceitos pertinentes à garantia do respeito aos direitos humanos.

Imperioso o esforço diante dos mais "elevados padrões éticos, profissionais, científicos na proteção e promoção da utilização segura de medicamentos" de forma compartilhada da comunicação entre o público e os pacientes, diante das novas formas de organização e convivência social, alterando o seu entorno, sua contingencia e complexidade a fim de promover uma nova estruturação diante dessas práticas desrespeitosas ${ }^{95}$.

As técnicas empregadas no desenvolvimento de medicamentos pediátricos devem constar nas bulas e rótulos dos fármacos nacionais, orientando pacientes e seus guardiões, de forma a favorecer seu uso racional e esclarecendo, sobre os dados conhecidos, até aquele momento, como sinônimo do seu direito humano à informação ${ }^{96}$. Ademais, sob o ponto de vista legal interno, o medicamento é uma mercadoria e, portanto, sujeito a legislação consumerista, também ${ }^{97}$.

95 OST, F. Legal System Between order and disorder. Oxford: Oxford University Press, 1994.

96 Vide RDC n. ${ }^{\circ} 71 / 09$ da ANVISA.

97 Artigos $6^{\circ}$ e 37 do Código de Defesa do Consumidor. 


\section{Revista da Faculdade Mineira de Direito $\mid$ V.20 N.40|178}

\section{Considerações Finais}

O estudo apontou a negligência estatal no tratamento dispensado aos pacientes pediátricos e seus guardiões legais, diante do desconhecimento do emprego das práticas cotidianas da "extrapolação de doses" e uso "off label" de medicamentos para crianças.

A complexidade da temática tornou-se pública e notória após a divulgação da importação do medicamento para leucemia infantil (asparaginase chinesa) pelo Ministério da Saúde brasileiro. Contudo, as informações disponibilizadas na imprensa desvirtuaram a compreensão pública nacional, os induzindo a pensar que apenas esse fármaco não possuía segurança e eficácia comprovadas.

A inexpressiva quantidade de estudos clínicos específicos para a população pediátrica é objeto de preocupação internacional, tanto que a Organização Mundial de Saúde (OMS), adota a Lista de Medicamentos Essenciais para Crianças (LMEc), como estratégia de condições mínimas de saúde. Nela constam orientações básicas sobre a administração, posologia e tratamentos médicos infantis, quando possíveis, diante da carência de medicamentos específicos para os seres em desenvolvimento. De certa forma, legítima o 'uso off label'.

A União Europeia, Estados Unidos, Canadá, Japão atentos aos entraves éticos e jurídicos na realização de estudos clínicos pediátricos desenvolveram estratégias próprias de incentivo nesse segmento industrial, tais como a prorrogação do prazo da patente, além da criação do Conselho Internacional de Harmonização ( $\mathrm{ICH}$ ), competente na articulação dos requisitos técnicos para produtos farmacêuticos de uso humano, através de diretrizes próprias de boas práticas clínicas. Além delas, nada existe, sobre experiências clínicas, envolvendo crianças.

O óbice dessa realidade é a preconizada proteção integral prevista na Convenção dos Direitos da Criança, como cuidado aos seres em desenvolvimento, considerados "incompletos como pessoa". Dessa forma, crianças possuem autonomia limitada perante a lei, ou seja, não são detentoras de desejo ou vontade própria, exigindo guardiões, que as representam nos seus anseios. 


\section{Revista da Faculdade Mineira de Direito | v.20 N.40|179}

O abrigo jurídico concedido às crianças é tanto, que ocasiona a não realização de estudos clínicos em seu próprio benefício. Ao revés, os proclama a "cobaias indiretas", pois seus tratamentos de saúde são realizados na perspectiva da "tentativa versus erro", como demonstrado. A solução viável é a extrapolação de doses, a partir da bioequivalência, no sentido de comparar resultados fisiológicos satisfatórios, os protegendo de riscos desnecessários e, viabilizando acesso à cuidados de saúde.

A perplexidade jurídica reside no fato de seus guardiões desejarem tratamentos confiáveis e seguros, mas não permitem, na grande maioria, que seus tutelados, sejam investigados, contribuindo para o dilema dos "órfãos terapêuticos".

Compreendemos a dificuldade técnica em resolver o impasse, porém, preconizamos que o instituto protetivo da representação legal, necessita ser rediscutido diante do princípio do melhor interesse das crianças, aliado ao progresso científico e tecnológico. Porém, não compactuamos com a não publicização dessa realidade, nos rótulos ou bulas dos respectivos medicamentos, as configurando como ofensiva aos direitos infantis. Internamente, conflita com os princípios informacionais previstos no Código de Defesa do Consumidor (Lei n. ${ }^{\circ}$ 8078/90).

Imperioso, portanto, uma abertura na definição da capacidade jurídica das crianças no intuito de equilibrá-la com o desenvolvimento de mecanismos que respeitem a dignidade dos pacientes pediátricos, evitando sua desconsideração. A Convenção dos Direitos das Crianças permanece sendo o marco mínimo de reconhecimento e respeito aos direitos infantis, sendo o parâmetro na adequação de práticas e políticas dos países que a ratificaram, sem prejuízo com as legislações internas e seus aspectos culturais próprios, típico dos tratados internacionais.

A partir desta constatação, é urgente que o Brasil, signatário dos mesmos documentos internacionais que preconizam o respeito aos direitos humanos, atente para a necessidade de estabelecer políticas públicas exclusivas aos órfãos terapêuticos nacionais, não apenas considerando-os "adultos em miniatura". Necessário que sejam adotadas práticas de respeito aos seus "cidadãos infantis", seja internacionalizando 


\section{Revista da Faculdade Mineira de Direito $\mid$ v.20 N.40 180}

algum dos modelos estrangeiros (ou outro, não estudado aqui), com o intuito de avançar na resolução de tal problemática.

A alternativa imediata viável é a de indicar na bula ou no rótulo o emprego da técnica da bioequivalência no desenvolvimento da extrapolação de doses, a semelhança do que ocorre com a Lei dos Medicamentos Genéricos, facilitando a escolha consciente de seus consumidores (prescritores, cuidadores ou pacientes).

Ademais, diante do princípio da autonomia, sendo devidamente informados, serão livres nas respectivas escolhas. Poderiam inclusive, desejar optar por participar de ensaios clínicos, proporcionando o avanço do conhecimento científico nessa seara, contribuindo para a melhoria da qualidade de vida e, pretensiosamente num futuro próximo, cooperar para a erradicação das moléstias infantis, possibilitando que seja definitivamente abandonada a técnica do erro e acerto, como vem sendo realizado.

\section{Referências}

AGÊNCIA NACIONAL DE VIGILÂNCIA SANITÁRIA (Anvisa). Manual das boas práticas em biodisponibilidade: bioequivalência/Agência Nacional de Vigilância Sanitária. Gerência Geral de Inspeção e Controle de Medicamentos e Produtos. Brasília. ANVISA, 2002.

Manual para notificação de eventos adversos e monitoramento de segurança em ensaios clínicos/Brasília. Anvisa. 2016.

ARIÉS, Philipe. História da criança e da família. Tradução Dora Flaksman. $2^{\mathrm{a}}$ ed. Rio de Janeiro: Guanabara, 1986.

ASSOCIAÇÃO MÉDICA MUNDIAL. Declaração de Helsinki I. Adotada na $18^{a}$ Assembleia Medica Mundial, Helsinki, Finlândia. 1964. Disponível em < https://www.ufrgs.br/bioetica/helsin1.htm>. Acesso em 20 de jun. de 2017.

BRASIL. LEI No 8.078, DE 11 DE SETEMBRO DE 1990. Dispõe sobre a proteção do consumidor e dá outras providências. Disponível em < http://www.planalto.gov.br/ccivil_03/leis/L8078.htm>. Acesso em 23 jun. 2017

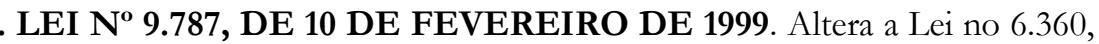
de 23 de setembro de 1976, que dispõe sobre a vigilância sanitária, estabelece o 


\section{Revista da Faculdade Mineira de Direito $\mid$ V.20 N.40|181}

medicamento genérico, dispõe sobre a utilização de nomes genéricos em produtos farmacêuticos e dá outras providências. Disponível em <http://www.planalto.gov.br/ccivil_03/leis/L9787.htm.> Acesso em 18 jun.2017.

LEI N. ${ }^{\circ}$ 10.406, DE 10 DE JANEIRO DE 2002. Institui o Código Civil. Disponível em < http://www.planalto.gov.br/ccivil_03/leis/2002/L10406.htm>. Acesso em 20 jun. 2017.

Ministério da Saúde. Secretaria Executiva. Subsecretaria de Assuntos Administrativos. Coordenação Geral de Material e Patrimônio. Extrato de dispensa de licitação n. ${ }^{\mathbf{6}}$ 62/2017 - UASG 2500005. N Processo: 25000049403201653 . Objeto: Aquisição de Asparaginase 10.000UI. Diário Oficial da República Federativa do Brasil. Brasília, 13 de janeiro de 2017, seção 3, p.84. Disponível em < http:/ / pesquisa.in.gov.br/imprensa/jsp/visualiza/index.jsp?jornal $=3 \&$ pagina $=84 \& d$ ata $=13 / 01 / 2017>$. Acesso em 18 jun. 2017.

BELOFF, Mary. Derecho, infância y família. Editorial Gedisa. Barcelona, 2000. Disponível em < https://issuu.com/ultimosensalir/docs/familia-beloff/232>. Acesso em 6 jan. 2017.

. Modelo de la protección integral de los derechos del niño y de la situación irregular: un modelo para armar y otro para desarmar. Justicia y Derechos del Niño, Santiago del Chile, n. 1, p. 9-21, nov. 1999. Disponível em: $<$ https://www.unicef.org/argentina/spanish/ar_insumos_PEJusticiayderechos1.pdf >. Acesso em: 7 jan. 2017.

. Protección integral de derechos del niño vs derechos em situacion irregular in Los derechos del niño em el sistema interamericano. Del Puerto, Buenos Aires, 2004.

BOBBIO, Marco. O doente imaginado: os riscos de uma medicina sem limites. Tradução de Mônica Gonçalves. São Paulo: Bamboo, 2014.

BRUÑOL, Miguel Cillero. El intersés superior del niño en el marco de la convención internacional sobre los derechos del niño in Infancia, ley y democracia em America Latina. García Méndez y Beloff, Mary (comps.). Ed. Temis/Depalma, Bogotá. $1^{a}$ ed. 1998. 


\section{Revista da Faculdade Mineira de Direito $\mid$ v.20 N.40|182}

CALDWELL, Patrina HY. MURPHY, Sharon B. BUTOW, Phyllis N. CRAIG, Jonathan C. Clinical trials in children. The Lancet. Volume 364, No. 9436, p803811, 28 August 2004. Disponível em < http://www.thelancet.com/journals/lancet/article/PIIS0140673604169420/abstract >. Acesso em 21 dez. de 2016.

CARvalho, Paulo. R. A. CARVAlHO, Clarrissa G. ALIEVI, Patrícia T. MARTINBIANCHO, Jaqueline. TROTTA, Eliana A. Identificação de medicamentos "não apropriados para crianças" em prescrições de unidade de tratamento intensivo pediátrico. Jornal de Pediatria. Porto Alegre, v. 79, n. 5, 2003. Disponível em <https://www.inf.pucrs.br/linatural/corporas/pediatria/txt/03-7905-397port.txt>. Acesso em 16 de set. 2015.

CARVAlHO, Patrícia Luciane de. Patentes Farmacêuticas e acesso a medicamentos. São Paulo: Atlas, 2007.

CECI, A. FELISI M., CATAPANO M., BAIARDI P. CIPOLLINA L., RAVERA S., BAGNULO S. REGGIO S. RONDINI G. Medicines for children licensed by the European Agency for the evaluation of medical products. Eur J Clin Pharmacol, v. 58, p. 495-500, 2002. Disponível em < https://www.ncbi.nlm.nih.gov/pubmed/12451425>. Acesso em 30 de out. de 2016.

CHAPPUY, F. DOZ, S. BLANCHE, GENTET, J-C. TRÉLUYER, J-M. Parental consent in paediatric clinical research. Arch Dis Child. 2006 Feb; 91(2): 112-116. Published online 2005 Oct 24. doi: 10.1136/adc.2005.076141. Disponível em < https://www.ncbi.nlm.nih.gov/pmc/articles/PMC2082705/>. Acesso em 21de dez. 2016.

CIDH. Comissão Interamericana de Direitos Humanos. Acceso a la información en matéria reproductiva desde uma perspectiva de derechos humanos. OEA/Ser.L/V/II. 22 noviembre 2011. Disponível em https://www.oas.org/es/cidh/mujeres/docs/pdf/ACCESO\%20INFORMACION \%20MUJERES.pdf. Acesso em 30 out. de 2016.

Caso Claude Reyes y otros Vs Chile. Sentencia de 19 de septiembre de $2006 . \quad$ Disponível em http:///www.corteidh.or.cr/docs/casos/articulos/seriec_151_esp.pdf. Acesso em 28 out. 2016. 


\section{Revista da Faculdade Mineira de Direito $\mid$ v.20 N.40|183}

. Caso F.S v Chile. Informe n. ${ }^{\circ}$ 52/14. Peticion 112-09. Disponível em http://www.oas.org/es/cidh/decisiones/2014/CHAD112-09ES.pdf. Acesso em 30 out. 2016.

Caso I. V vs Bolívia. Informe n. $.^{\circ} 40 / 08$. Petition n. ${ }^{\circ} 270-07.3$ de julio de 2008. Disponível em https://www.cidh.oas.org/annualrep/2008sp/Bolivia27007.sp.htm. Acesso em 30 out. 2016.

COELHO, H. L. L. et al. A critical comparison between the World Health Organization list of essential medicines for children and the Brazilian list of essential medicines (Rename). Jornal de Pediatria, Porto Alegre, v. 89, n. 2, p. 171-178, mar./abr. 2013.2 Disponível em: <http://apps.who.int/medicinedocs/documents/s22184pt/s22184pt.pdf>. Acesso em: 27 jan. 2017.

COMISSÃO EUROPEIA. Relatório da Comissão ao Parlamento Europeu e ao Conselho. Melhores Medicamentos para Crianças - do Conceito à Realidade. Relatório geral sobre a experiência adquirida com a aplicação do Regulamento (CE) n. ${ }^{\circ}$ 1901/2006 relativo a medicamento para uso pediátrico. Bruxelas, 2013. Disponível em http://ec.europa.eu/health/files/pharmacos/docs/doc2002/feb/cd_pediatrics_en.p df. Acesso em 22 de set. 2015.

DWORKIN, Ronald. Domínio da vida: aborto, eutanásia e liberdades individuais. São Paulo: Martins Fontes, 2003.

ECRH. Case of Gaskin vs The United Kingdom. Application n. ${ }^{\circ}$ 10454/83. Sentencia de 7 july de 1989. Disponível em http://www.juridischeuitspraken.nl/1989070EHRMGaskin.pdf. Acesso em 28 out 2016.

Case of Gilberg vs Sweden. Aplication n. ${ }^{\circ} 41723 / 06$. Sentencia de 3 april de 2012. Disponível em http://menschenrechte.ac.at/orig/12_2/Gilberg.pdf. Acesso em 28 out. 2016.

. ECRH. Case of Open Door and Dublin Well Woman v. Ireland. N. ${ }^{\circ}$ 64/1991. Council of Europe: European Court of Human Rights, 23 september 1992. Disponível em http://www.refworld.org/docid/3ae6b7020.html. Acesso em 28 out. 2016. 


\section{Revista da Faculdade Mineira de Direito | v.20 N.40|184}

EEKELAR, John. Commentary on "True Wishes" in The Johs Hopkins University Press. PPP/Vol. 2, N. ${ }^{\circ}$ 4/December .1995.

ERNEST TB, ELDER DP, MARTINI LG, ROBERTS M, FORD JL. Developing paediatric medicines: identifying the needs and recognizing the challenges. J Pharm

Pharmacol. 2007 Aug;59(8):1043-55. Disponível em < https://www.ncbi.nlm.nih.gov/pubmed/17725846>. Acesso em 13 dez. 2016.

EUROPEAN MEDICINES AGENCY (EMA). Committee for Medicinal Products for Human Use (CHMP). EMEA/CHMP/PEG/194810/2005. Reflection paper: formulations of choice for the paediatric population. London, 28 july 2006. Disponível em: <http://www.ema.europa.eu/docs/en_GB/document_library/Scientific_guideline/ 2009/09/WC500003782.pdf>. Acesso em: 14 dez. 2016.

ICH Topic E 11 Clinical Investigation of Medicinal Products in the Paediatric Population. Note for Guidance on Clinical products in the paediatric population (CPMP/ICH/2711/99). Disponível em http://www.ema.europa.eu/docs/en_GB/document_library/Scientific_guideline/20 09/09/WC500002926.pdf. Acesso em 22 de nov. de 2016.

FARMACÊUTICA LEVANTA NOVAS DÚVIDAS SOBRE REMÉDIO PARA CÂNCER INFANTIL Fantástico. São Paulo. Rede Globo, 2 abr. 2017. PROGRAMA $\mathrm{DE}$ TV. Disponível em <http://g1.globo.com/fantastico/noticia/2017/04/farmaceutica-levanta-novasduvidas-sobre-remedio-para-cancer-infantil.html>. Acesso em 15 maio 2017.

KIMLAND E., NYDERT P., BÖTTIGER Y. LINDEMALM S. Paediatric drug use with focus on off-label prescriptions at Swedish hospitals - a Nationwide study. Acta Paediatr (2002) $101 \quad$ (7):772-8. Disponível em http://onlinelibrary.wiley.com/doi/10.1111/j.1651-2227.2012.02656.x/abstract. Acesso em 3 jan. 2017.

KRESS, Hartmut. Ética Médica. São Paulo: Loyola, 2008.

GAUDERER, E. C. Os direitos do paciente: um manual de sobrevivência. 6. ed. São Paulo: Record, 1988. 


\section{Revista da Faculdade Mineira de Direito $\mid$ v.20 N.40|185}

HOSSNE, W. S. A regulamentação de pesquisas com seres humanos. In Bioética e Saúde Pública. FORTES, P. A. C.; ZOBOLI, E. L. P. (Orgs.). São Paulo: Loyola, 2004.

HUNT, Paul; KHOSLA, Rajat. Acesso a medicamentos como um direito humano. Sur - Revista Internacional de Direitos Humanos, São Paulo, v. 5, n. 8, p. 100121 jun. 2008. Disponível em: <http://www.scielo.br/pdf/sur/v5n8/v5n8a06.pdf> Acesso em: 15 fev. 2017.

ILLICH. Ivan. A expropriação da saúde. Nemesis da Medicina. Tradução de José Kosinski de Calvancanti. $3^{\text {a }}$ ed. Editora Nova Fronteira, 1975.

INTERNATIONAL CONFERENCE ON HARMONISATION OF TECHNICAL REQUIREMENTS FOR REGISTRATION OF PHARMACEUTICALS FOR HUMAN USE (ICH). E8: General Considerations for Clinical Trials. Geneva, 17 july 1997. Disponível em: <http://www.ich.org/fileadmin/Public_Web_Site/ICH_Products/Guidelines/Effic acy/E8/Step4/E8_Guideline.pdf>. Acesso em: 6 dez. 2016.

M3(R2): Guidance on Nonclinical Safety Studies for the Conduct of Human Clinical Trials and Marketing Authorization for Pharmaceuticals. Geneva, 11 june 2009. Disponível em: <http://www.ich.org/fileadmin/Public_Web_Site/ICH_Products/Guidelines/Multi disciplinary/M3_R2/Step4/M3_R2_Guideline.pdf>. Acesso em: 6 dez. 2016.

E1: The extent of population exposure to assess clinical safety for drugs intended for long-term treatment of non-life-threatening conditions E1. 27 october 1994.

Disponível em http://www.ich.org/fileadmin/Public_Web_Site/ICH_Products/Guidelines/Effica cy/E1/Step4/E1_Guideline.pdf>. Acesso em: 27 de nov. de 2016.

Q9: Quality Risk Management. 9 November 2005. Disponível em https://www.ich.org/fileadmin/Public_Web_Site/ICH_Products/Guidelines/Quali ty/Q9/Step4/Q9_Guideline.pdf.Acesso em 6 dez. 2016.

JOSEPH DP, CALDWELLa PHY, CRAIG JC. Registered paediatric clinical trials: a global context. 2013. Poster presentation International Congress of Pediatrics 2013 (ICP), The 27th Congress of International Pediatric Association 24-29 August 2013 Melbourne, Australia. 


\section{Revista da Faculdade Mineira de Direito | v.20 N.40|186}

MARTINS, Natália Camboa. Sequestro internacional de crianças: análise de posições judiciais sobre as exceções à obrigação de retorno previstas na Convenção de Haia de 1980 sobre os aspectos civis do sequestro internacional de crianças. 2011. 270 p. Dissertação (Mestrado em Direito) - Programa de Pós Graduação em Direito, Centro Universitário de Brasília, Brasília, 2011.

NAÇÕES UNIDAS (ONU). A/RES/44/25: Convenção sobre os Direitos da Criança. Adotada e aberta para assinatura, ratificação e adesão da Assembleia Geral, em 20 de novembro de 1989, entrada em vigor em 2 de setembro de 1990. Disponível em < http://www.ohchr.org/en/professionalinterest/pages/crc.aspx. Acesso em: 14 jun. 2017.

A/64/272: Derecho de toda personal disfrute del más alto nível posible de salud física y mental. Observacion General n. ${ }^{\circ} 14$ Proclamada em 11 de agosto de $2000 . \quad$ Disponível em < http://www.acnur.org/t3/fileadmin/Documentos/BDL/2001/1451.pdf $>$. Acesso em 19 jun. 2017.

A/RES/217/A: Declaração dos Direitos Humanos. Proclamada pela Assembleia Geral das Nações Unidas em Paris, em 10 de dezembro de 1948 Disponível em < https://nacoesunidas.org/direitoshumanos/declaracao/>. Acesso em 15 jun. 2017.

. Comité de los Derechos del Niño. CRC/C/GC/15: Observación general No 15 (2013) sobre el derecho del niño al disfrute del más alto nivel posible de salud (artículo 24). Ginebra, 17 abr. 2013. Disponível em: $<$ http://www.codajic.org/sites/www.codajic.org/files/Convenci\%C3\%B3n $\% 20$ sob

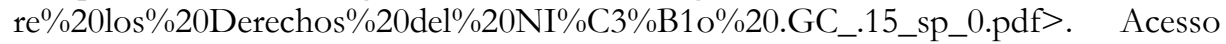
em: 13 nov. 2016

OEA. Inter-American Comissiono $n$ Human Rights. Office of the Special Rapporteur on Freedom of Expression. El derecho de acesso a la informacion em el marco jurídico interamericano. Relatoria especial para la liberdad de expresión. Comisión Interamericana de Derechos Humanos. OEA Ser.L/V/II CIDH/RELE/INF. 2009.

OST, F. Legal System Between order and disorder. Oxford: Oxford University Press, 1994. 


\section{Revista da Faculdade Mineira de Direito $\mid$ V.20 N.40|187}

RAMET, José. What the paediatricians need the launch of paediatric research in Europe. European Journal of Pediatrics, Berlin, v. 164, n. 5, p. 263-265, may 2005. Disponível em: <http://dx.doi.org/10.1007/s00431-005-1633-z>. Acesso em: 23 set. 2016.

RAMOS, Karina Alves; JUNGES, Fernanda. O uso off label de medicamentos e a busca por evidências orientadoras de conduta: uma abordagem necessária. Disponível em http://www.cpgls.pucgoias.edu.br/7mostra/Artigos/SAUDE\%20E\%20BIOLOGI CAS $/ \mathrm{O} \% 20$ uso $\% 20$ off $\% 20$ label $\% 20$ de $\% 20$ medicamentos $\% 20 \mathrm{e} \% 20 \mathrm{a} \% 20 \mathrm{busca} \% 20$ por $\% 20$ evidencias $\% 20$ orientadoras $\% 20 \mathrm{de} \% 20$ conduta.pdf $>$. Acesso em 19 jun. 2017.

REDIGUIERI, Camila Fracalossi; SOARES, Kelen; CARRIJO, Kalinka de Melo. Bioisenção. In: VIEIRA, Fernanda Pires; REDIGUIERI, Camila Fracalossi; REDIGUIERI, Carolina Fracalossi. (Orgs.). A regulação de medicamentos no Brasil. Porto Alegre: Artmed, 2013. p. 320-336.

REDIGUIERI, Camila Fracalossi; SOUZA, Varley Dias. Estudos de Bioequivalênca. In: VIEIRA, Fernanda Pires; REDIGUIERI, Camila Fracalossi; REDIGUIERI, Carolina Fracalossi. (Orgs.). A regulação de medicamentos no Brasil. Porto Alegre: Artmed, 2013. p. 237-290.

ROBERTS, Rosemary. RODRIGUEZ, William. MURPHY, Dianne. CRESCENZI, Terri. Pediatric drug labeling: improving the safety and eficacy of pediatric therapies. Journal of the American Medical Association, v. 290, p. 905-911, 2003. Disponível em < http://jamanetwork.com/journals/jama/fullarticle/197130>. Acesso em 3 jan. 2017.

SHIRKEY, Harry. Editorial Coment: Therapeutic Orphans. The Journal of Pediatrics, Cincinnati, v. 72 , n. 1, p. 119-120, jan. 1968. Disponível em: <http://www.jpeds.com/article/S0022-3476(68)80414-7/pdf>. Acesso em: $21 \mathrm{dez}$. 2016.

SUTCLIFFE, Alastair G. Prescribing medicines for children: Major problems exist, but there are some promising developments. BMJ. 1999 Jul 10; 319(7202): 70-71. Disponível em < https://www.ncbi.nlm.nih.gov/pmc/articles/PMC1116223/>. Acesso em 22 dez. 2016. 


\section{Revista da Faculdade Mineira de Direito $\mid$ v.20 N.40|188}

TRIBUNAL INTERNACIONAL DE NUREMBERG. 1947 - Trials of war criminal before the Nuremberg Military Tribunals. Control Council Law 1949;10(2):181-182. Disponível em https://www.ufrgs.br/bioetica/nuremcod.htm. Acesso em 20 de jun. de 2017.

UNITED NATIONS CHILDREN'S FUND (UNICEF). Ann Veneman no Prólogo do relatório Situação Mundial da Infância. Edição especial. Novembro de 2009. Disponível em < https://www.unicef.org/brazil/pt/sowc_20anosCDC.pdf>. Acesso em 6 nov. 2016.

VARELLA, Marcelo D. Direito Internacional Público. Editora Saraiva. 6. ed. - São Paulo, 2016.

- Internacionalização do Direito: direito internacional, globalização e complexidade - Brasília: UniCEUB, 2013

WORLD HEALTH ORGANIZATION (WHO). 6th List. Model List of Essential Medicines for Children. 6th List. March 2017. Disponivel em http://www.who.int/medicines/publications/essentialmedicines/6th_EMLc2017.pd f?ua $=1$. Acesso em 20 jun. 2017.

Promoting Safety of Medicines for Children. Geneva: World Health Organization, 2007. Disponível em: <http://www.who.int/medicines/publications/essentialmedicines/Promotion_safe_ med_childrens.pdf>. Acesso em: 15 dez. 2016.

EB109/8. Executive Board: 109th Session. Geneva, 7 dec. 2001. Disponível em:

<http://www.who.int/selection_medicines/committees/subcommittee/2/eeb1098 $\% 5 B 1 \% 5$ D.pdf $>$. Acesso em: 20 nov. 2016.

. The importance of pharmacovigilance: safety monitoring of medicinal products. $\quad$ Geneva, 2002. Disponível em http://who.int/iris/bistream/10665/42493/1/a/75646.pdf. Acesso em: 18 de dez. de 2016.

The use of essential drugs: Ninth report of the WHO Expert Committee (including the revised Model List of Essential Drugs). Geneva: World Health 


\section{Revista da Faculdade Mineira de Direito $\mid$ V.20 N.40|189}

Organization, 2000. (WHO technical report series, 895). Disponível em: <http://apps.who.int/iris/bitstream/10665/42373/1/WHO_TRS_895.pdf>. Acesso em: 9 dez. 2016.

YOUNG, Bridget. SHILLING, Valerie. HICKEY, Helen. SOWDEN, Emma. SMYTH, Rosalind. WILLIAMSON, Paula. What parents think about being approached about children's trials, how this differs from what practitioners expect, and what this tells us about enhancing recruitment. Trials. 2011; 12(Suppl 1): A116. Published online 2011 Dec 13. doi: 10.1186/1745-6215-12-S1-A116. Disponível em < https://www.ncbi.nlm.nih.gov/pmc/articles/PMC3287689/>. Acesso em: 20 dez. 2016. 